This is the accepted version of this paper before copy-editing, formatting, technical enhancements and pagination. The finally published version (version of record) can be found via https://doi.org/10.1016/j.advwatres.2016.08.001 (C) 2016. This manuscript version is made available under the CC-BY-NC-ND 4.0 license https://creativecommons.org/licenses/by-nc-nd/4.0/

\title{
Root-zone plant available water estimation using the SMOS-derived Soil Water Index
}

\author{
Ángel González-Zamora ${ }^{\mathrm{a} *}$, Nilda Sánchez ${ }^{\mathrm{a}}$, José Martínez-Fernández ${ }^{\mathrm{a}}$, Wolfgang Wagner ${ }^{\mathrm{b}}$ \\ ${ }^{a}$ Instituto Hispano Luso de Investigaciones Agrarias, University of Salamanca, Duero 12, 37185, \\ Villamayor, Spain. aglezzamora@usal.es, nilda@usal.es, imf@usal.es \\ ${ }^{\mathrm{b}}$ Department of Geodesy and Geoinformation, Vienna University of Technology, Gußhausstr. \\ 25-29 / E120 (CB0321) 1040 Vienna, Austria.wolfgang.wagner@geo.tuwien.ac.at
}

*Corresponding author: Instituto Hispano Luso de Investigaciones Agrarias, University of Salamanca, Duero 12, 37185, Villamayor, Spain. aglezzamora@usal.es, +0034 923294400

\begin{abstract}
Currently, there are several space missions capable of measuring surface soil moisture, owing to the relevance of this variable in meteorology, hydrology and agriculture. However, the Plant Available Water (PAW), which in some fields of application could be more important than the soil moisture itself, cannot be directly measured by remote sensing. Considering the root zone as the first $50 \mathrm{~cm}$ of the soil, in this study, the PAW at $25 \mathrm{~cm}$ and $50 \mathrm{~cm}$ and integrated between 0 and $50 \mathrm{~cm}$ of soil depth was estimated using the surface soil moisture provided by the Soil Moisture Ocean Salinity (SMOS) mission. For this purpose, the Soil Water Index (SWI) has been used as a proxy of the root-zone soil moisture, involving the selection of an optimal T $\left(T_{\text {opt }}\right)$, which can be interpreted as a characteristic soil water travel time. In this research, several tests using the correlation coefficient (R), the Nash-Sutcliffe score (NS), several error estimators and bias as predictor metrics were applied to obtain the $T_{\text {opt, }}$ making a comprehensive study of the T parameter. After analyzing the results, some differences were found between the $T_{\text {opt }}$ obtained using R and NS as decision metrics, and that obtained using the errors and bias, but the SWI showed good results as an estimator of the root-zone soil moisture. This index showed good agreement, with an $\mathrm{R}$ between 0.60 and 0.88 .

The method was tested from January 2010 to December 2014, using the database of the Soil Moisture Measurements Stations Network of the University of Salamanca (REMEDHUS) in Spain. The PAW estimation showed good agreement with the in situ measurements, following closely the dry-downs and wetting-up events, with $\mathrm{R}$ ranging between 0.60 and 0.92 , and error values lower than $0.05 \mathrm{~m}^{3} \mathrm{~m}^{-3}$. A slight underestimation was observed for both the PAW and root-zone soil moisture at the different depths; this could be explained by the underestimation pattern observed with the SMOS L2 soil moisture product, in line with previous studies. Nevertheless, the results obtained in this research showed an encouraging improvement of the PAW estimation. Despite the need for more research on this issue, the results of this study show that this methodology can be useful for applications of great interest in agriculture and hydrology.
\end{abstract}

Keywords: SMOS; Soil moisture; Root-zone; Soil Water Index; Plant Available Water

\section{Highlights}

Plant Available Water (PAW) was estimated using the SMOS L2 soil moisture product. SMOS-derived SWI and PAW were validated at different depths with the REMEDHUS network. Several tests using different metrics were applied for obtaining the $T_{\text {opt }}$. Comparison with in situ yielded $\mathrm{R}$ greater than 0.9 and errors lower than $0.04 \mathrm{~m}^{3} \mathrm{~m}^{-3}$. 


\section{INTRODUCTION}

Soil moisture was declared an Essential Climate Variable (ECV) in 2010 by the World Meteorological Organization because it plays an important role in several hydrologic and atmospheric processes (Legates et al. 2011). There are a variety of methods to measure soil moisture, which can be separated into ground based/in situ measurements and airborne/satellite-based approaches (Paulik et al. 2014). Regarding the first group, there are currently few networks that measure soil moisture in comparison with the vast number of climatic networks in the world. However, the number of in situ soil moisture networks is growing. The main advantage of the ground observations is their temporal resolution and that they represent the only direct measurement of soil moisture at different depths, but the main limitation is that they provide only discrete point-scale measurements over a limited soil volume. Alternatively, remotely sensed soil moisture has the advantage of covering large areas and identifying large-scale events (Ochsner et al. 2013), providing useful information on soil moisture spatio-temporal variability. The soil moisture observation by remote sensing is made in the first few centimeters of soil, depending on soil characteristics and wetness conditions (Delwart et al. 2008). However, in some cases, such as drought monitoring and agricultural modeling, the estimation of the root-zone soil moisture (RZSM) is more important because it represents the reservoir of the plant available water (PAW).

Several sensors and systems have been used to measure soil moisture globally, e.g., the European Remote Sensing Scatterometer (ERS) (Wagner et al. 1999), the Advanced Microwave Sounding Radiometer for Earth Observation System (AMSR-E) and the AMSR-2 (Njoku et al. 2003) or the Advanced Scatterometer (ASCAT) (Bartalis et al. 2007). The soil moisture database provided by these sensors, among others, is included in the Climate Change Initiative (CCI) project for soil moisture (http://www.esa-soilmoisture-cci.org/) created by the European Space Agency (ESA). The Soil Moisture Ocean Salinity (SMOS) (Kerr et al. 2010) and Soil Moisture Active Passive (SMAP) mission (Entekhabi et al. 2010) were launched in 2009 and 2015, respectively, and are providing continuous estimations of soil moisture worldwide.

Obtaining RZSM measurements with high accuracy is challenging, because it cannot be directly observed by remote sensing. Research has addressed the relationships between different vegetation indices from MODIS or Landsat satellites, e.g., the Normalized Difference Vegetation Index (NDVI) and the Enhanced Vegetation Index (EVI) with the RZSM (Wang et al. 2007; Crow et al. 2008; Schnur et al. 2010; Liu et al. 2012; Bezerra et al. 2013; Santos et al. 2014). The vegetation indices can quantify the leaf area and the health and vigor of the vegetation, which are influenced in turn by climate and soil moisture content, among other factors (Liu et al. 2012). However, all these studies concluded that plants take time to respond to changes in atmospheric conditions and this factor needs to be taken into account when the vegetation indices are used to estimate RZSM, which makes all these methods for estimating RZSM less appropriate for use in near real-time.

Another method used for RZSM estimation is the combination of remotely sensed soil moisture with different models using data assimilation techniques. Sabater et al. (2007) used different Kalman filter techniques to assimilate soil moisture observations into the Interaction between the Soil Biosphere and Atmosphere (ISBA) model. Renzullo et al. (2014) used the same techniques in the Australian Water Resources Assessment Landscape (AWRA-L) model to estimate RZSM from $20 \mathrm{~cm}$ to $1 \mathrm{~m}$ of soil depth. The MERRA model was used in Rienecker et al. (2011), whereas the Soil Vegetation Atmosphere Transfer (SVAT) model was used in Crow et al. (2008) or the ORCHIDEE model in Rebel et al. (2012). The SMAP Level 4 Soil Moisture product is the first product to provide assimilated soil moisture operationally in the RZSM $(0-100 \mathrm{~cm})$. SMAP L-band brightness temperature data are assimilated into a land surface model that is gridded using an Earth-fixed, global, cylindrical $9 \mathrm{~km}$ Equal-Area Scalable Earth Grid (EASE-Grid 2.0) projection (Koster et al. 2015). All these models have the drawback of a high 
computational cost. The same problem is presented in studies where machine learning models are used (Zaman and McKee 2014).

Previous studies suggested that RZSM is well correlated with near-surface soil moisture (Mahmood and Hubbard 2007), however, the strength of this correlation is locationdependent, in particular when considering short time scales. Therefore, satellite soil moisture retrievals may provide an accurate means of estimating water content in the soil root-zone (Ford et al. 2014). One of the methods used to estimate RZSM is based on the Soil Water Index (SWI), an exponential filter developed by Wagner et al. (1999) and rewritten in a recursive form by Albergel et al. (2008). This method estimates the soil moisture profile from surface observations using only one parameter $(T)$, which is related to the water travel time along the soil profile. This variable has been calculated in many different ways, yielding widely varying results (Wagner et al. 1999; Albergel et al. 2008; Brocca et al. 2011). SWI has been widely used and validated with previous soil moisture products from different satellites (Wagner et al. 1999; Brocca et al. 2011; Albergel et al. 2012; Paulik et al. 2014), hence now it is also being used with SMOS (Ford et al. 2014; Laiolo et al. 2015). While many studies have looked into the temporal behavior of the SWI, only a few studies have addressed whether this equation provides a reasonably good estimate of the absolute soil moisture level. Once the SWI is estimated, the PAW can be obtained through different models.

This work aims to obtain the PAW best estimation from the SMOS-derived SWI using the L2 surface soil moisture series and soil water parameters. The PAW was calculated with the model proposed by Wagner et al. (1999) together with the SWI recursive algorithm proposed by Albergel et al. (2008). For this purpose, the SMOS L2 Soil Moisture product, SMUDP (v.5.51) was used from January 2010 to December 2014. The soil moisture measurements over the REMEDHUS network were used as the benchmark dataset for testing the methodology. Moreover, a thorough study of the effect of the parameter T on the SWI was made using different metrics, prior to the PAW estimation. The objective was to delve into the alternatives for the T estimation, obtaining an optimal $T$ value for each soil moisture station and for the REMEDHUS area average. The ultimate goal is to test the feasibility of the remotely sensed surface soil moisture from SMOS to derive an added-value product useful for many applications.

\section{DATA SETS}

\subsection{In situ soil moisture data}

REMEDHUS is located in the Duero Basin $\left(41.1^{\circ}\right.$ to $41.5^{\circ} \mathrm{N} ; 5.1^{\circ}$ to $\left.5.7^{\circ} \mathrm{W}\right)$ over a semi-arid Mediterranean agricultural area of approximately $1300 \mathrm{~km}^{2}$ (Fig. 1), covered by rainfed cereals in most cases but also irrigated crops, vineyards and forest-pasture areas (Sánchez et al. 2012; González-Zamora et al. 2015). REMEDHUS is part of the International Soil Moisture Network, ISMN, (Dorigo et al. 2011), and it has been used in many validation studies of remotely sensed soil moisture products (Brocca et al. 2011; Sánchez et al. 2012; González-Zamora et al. 2015) including SWI (Ceballos et al. 2005; Paulik et al. 2014).

$<$ Insert Fig. 1 here>

This network is equipped with 12 automated stations that include capacitance probes (Hydra Probes, Stevens Water Monitoring System, Inc.) that measure the soil moisture hourly at $5 \mathrm{~cm}$, and two EnviroSMART probes (Sentek Pty. Ltd.) measuring soil moisture hourly at 25 and 50 $\mathrm{cm}$ soil depths (Table 1). Because the main land use is rainfed cereals (85\% of the area), the 0 $50 \mathrm{~cm}$ depth was considered representative of the soil root zone (Pietola and Alakukku 2005). In many previous experiments of validation, when comparing the in situ dataset with satellitederived soil moisture, it was found that there were no differences on the use of the daily average or the instantaneous value of the in situ soil moisture at the satellite overpass 
(Sanchez et al., 2012; Piles et al., 2014; Gonzalez-Zamora et al., 2015). For this reason, only the daily average (i.e., the 24 h-average) at 5,25 and $50 \mathrm{~cm}$ depth were used. Furthermore, due to the different soil volume monitored by the two probe types, a weighted average of the 0-50 $\mathrm{cm}$ soil moisture was also calculated (Martínez-Fernández et al. 2015):

$S M_{-50 \mathrm{~cm}}=\frac{S M_{5} \mathrm{~cm}}{5}+\frac{2 S M_{25} \mathrm{~cm}}{5}+\frac{2 S M_{50 \mathrm{~cm}}}{5}$

Thus, four in situ time series from the 12 stations resulted for 5,25 and $50 \mathrm{~cm}$ soil depths, together with the weighted $0-50 \mathrm{~cm}$. For this study, the number of measurements for each depth is 1826 in average.

$<$ Insert Table 1 here>

The soil water parameters field capacity $\left(\Theta_{\mathrm{FC}}\right)$, wilting point $\left(\Theta_{\mathrm{WP}}\right)$ and total water capacity $\left(\Theta_{\text {TwC }}\right)$ were obtained for each station and soil layer (Table 1$)$ from the calculation of the water retention curves of the soil monoliths taken at each depth where the soil moisture was measured. The retention curves were estimated by applying the van Genuchten (1980) method, measuring the soil moisture contents at nine soil-water potential values (from 0 to $1500 \mathrm{kPa}$ ) using sand boxes and pressure membrane.

\subsection{Satellite data set}

SMOS was launched by the European Space Agency (ESA) in November 2009. It is the first mission specifically dedicated to globally measuring the Earth's surface soil moisture, with an accuracy goal of $0.04 \mathrm{~m}^{3} \mathrm{~m}^{-3}$ and a revisit of 3 days since January 2010 (Kerr et al. 2010). In this research, the SMOS Level 2 Soil Moisture User Data Product (SMUDP2) version 5.51 was used. This product is delivered by ESA over an Icosahedral Snyder Equal Area Earth (ISEA-4H9) grid with equally spaced nodes at $\sim 15 \mathrm{~km}$, known as the Discrete Global Grid (DGG). A detailed description of the $L 2$ algorithm used for the retrievals is provided in Kerr et al. (2012). The soil moisture retrieval is associated with two quality flags, Data Quality Index (DQX) and Radio Frequency Interference (RFI_flag). In this work, the ascending and descending series were filtered out following the thresholds for the RFI_flag and DQX as suggested in (GonzálezZamora et al. 2015).

An average of the ascending and descending L2 soil moisture series was calculated daily using 1678 data (91.89\% of dates available for the whole study period) without any interpolation. In case of days with only one orbit, that orbit was only used.

\section{METHODOLOGY}

Prior to any calculation, the L2 SMOS series was compared to the ground measurements. To assess its accuracy, each DGG value was individually compared with each overlapping station. Additionally, the spatial average of the 6 DGGs and the 12 stations was used. These comparisons were made using the in situ soil moisture measurements at $5,25,50$ and $0-50 \mathrm{~cm}$ depth $\left(\mathrm{SM}_{25 \mathrm{~cm}}, \mathrm{SM}_{50 \mathrm{~cm}}\right.$ and $\left.\mathrm{SM}_{0-50 \mathrm{~cm}}\right)$. The correlation coefficient $(\mathrm{R})$, the root mean square difference (RMSD), the centered root mean square difference (CRMSD) and the bias were used.

\subsection{Calculation of Soil Water Index}

Albergel et al. (2008) used a recursive exponential filter to estimate the RZSM from nearsurface observations. This method assumes a two-layer soil, the first representing the remotely sensed topsoil layer, and the second layer that extends downwards from the bottom 
of the surface layer, and which represents the water reservoir (Wagner et al. 1999). The proposed model relates the past dynamics of the surface soil moisture content to the profile moisture using an exponential smoother filter instead of a linear relation, assuming that the soil moisture content integrated over the deeper layers exhibits much smaller variations than in the topmost layer. The recursive formulation was used to calculate the SWI (2). The filter is initialized with $\mathrm{SWI}_{(1)}=\mathrm{SM}\left(\mathrm{t}_{1}\right)$ and $\mathrm{K}_{1}=1$.

$S W I_{n}=S W I_{(n-1)}+K_{n}\left(S M\left(t_{n}\right)-S W I_{(n-1)}\right)$,

where $S W I_{(n-1)}$ is the predicted RZSM estimate at $t_{n-1}, S M\left(t_{n}\right)$ is the surface soil moisture estimate at $t_{n}$, and the gain $K$ at time $t_{n}$ is given by (3)

$K_{n}=\frac{K_{n-1}}{K_{n-1}+e^{-\frac{t_{n-1}-t_{n-1}}{T}}}$,

where T represents the timescale of the soil moisture variation, in days. This parameter can be interpreted as a characteristic time length for each type of soil, increasing with the depth of the reservoir and decreasing with the soil diffusivity constant. The T values appear to be highly variable in the literature, depending on the applications, study areas, sensors used or even between measurement locations within the same area (Albergel et al. 2008). Overall, the methods used to obtain the optimal $T$ value $\left(T_{\text {opt }}\right)$ can be clustered in three groups: those that compare SWI from remote sensing with in situ soil moisture measurements at different depths, others that compare SWI from remote sensing with modeled soil moisture data at different depths, and finally those that compare SWI from in situ soil moisture measurements with in situ depth soil moisture measurements; this study belongs to this last group. Albergel et al. (2008) showed that each study site had its $\mathrm{T}_{\mathrm{opt}}$, which was characterized by the highest prediction accuracy as assessed by the Nash-Sutcliffe (NS) score. Other studies used the best correlation coefficient between the SWI dataset and in situ measurements to select the $T_{\text {opt }}$ (Albergel et al. 2009; Paulik et al. 2014). In this work, a comprehensive study for calculating the $T_{\text {opt }}$ was made, using the NS score, R, RMSD, CRMSD and the bias as predictors of the $T_{\text {opt }}$. The best $T$ (ranging from 1 to 120 days) was determined by assessing with these metrics the comparisons between ground observations at 25, 50 and 0-50 layers from the 12 stations and the SWI calculated with the surface soil moisture. Thus, 120 values of SWI were obtained for each station and for the area average. The SWI calculated from the in situ surface soil moisture measurements (hereafter $S W I_{\text {Insitu }}$ ) was compared to $S_{25} M_{25}, S_{50 \mathrm{~cm}}$ and $S_{0-50 \mathrm{~cm}}$ obtaining the different metrics for each $T$ used. The $T_{\text {opt }}$ was selected based on the better metric in the different cases. For NS and R, the $T_{\text {opt }}$ corresponds to the highest NS and R values; for RMSD and CRMSD, the $T_{\text {opt }}$ corresponds to the lowest RMSD and CRMSD values; for bias, the $T_{\text {opt }}$ corresponds to the bias value nearest to zero.

The $T_{\text {opt }}$ obtained with in situ soil moisture values were applied afterwards to the SMOS L2 soil moisture product using equations (3) and (2), resulting in the SWI series calculated exclusively with satellite data (hereafter $S W I_{S M O S}$ ). The agreement between the resulting $S \mathrm{SW}_{S M O s}$ and the in situ $\mathrm{SM}_{25 \mathrm{~cm}}, \mathrm{SM}_{50 \mathrm{~cm}}$ and $\mathrm{SM}_{0-50 \mathrm{~cm}}$ series was assessed again with the former set of statistical metrics (R, RMSD, CRMSD and bias).

\subsection{Calculation of Plant Available Water}

For the PAW calculation, Wagner et al. (1999) proposed a model using the soil water parameters and the SWI (4):

$P A W=S W I\left(\frac{\theta_{F C}+\theta_{T W C}}{2}-\theta_{W P}\right)$, 
where SWI is the Soil Water Index obtained with $T_{\text {opt }}$ at each depth, and $\Theta_{\mathrm{FC}}, \Theta_{\mathrm{WP}}$ and $\Theta_{\mathrm{TWC}}$ stand for field capacity, wilting point and total water holding capacity, respectively. The $\Theta_{F C}$, $\Theta_{W P}$ and $\Theta_{T W C}$ used for the estimation of PAW ${ }_{0-50 \mathrm{~cm}}$ were calculated with the same weights for the different depths as used in equation (1). The agreement between the PAW calculated with

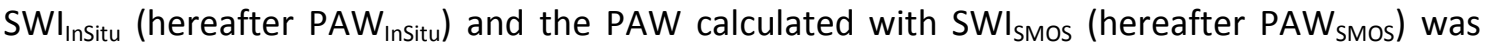
assessed with a set of statistical metrics (R, RMSD, CRMSD and bias).

\section{RESULTS AND DISCUSSION}

\subsection{Comparison between SMOS soil moisture and in situ soil moisture at different depths}

The time series of soil moisture (Fig. 2) reveals that the SMOS series has a larger dynamic range than the in situ series; for the three in situ measurements time series, the higher dynamic range, as expected, corresponds to the $5 \mathrm{~cm}$ depth. The deeper the measurement, the more limited the dynamic range and the smoother the curve. All the series showed a marked seasonality, corresponding with the climatic conditions in the area. During the summer periods, there is greater difference in the time series of in situ soil moisture at the various depths than there is in cold, rainy periods due to the higher temperature and surface evaporation that make the deep layers retain a higher water content. In contrast, soon after a rain event in the fall-winter periods, there is more water in the $5 \mathrm{~cm}$ than in the $25 \mathrm{~cm}$ or even the $50 \mathrm{~cm}$ depth owing to the delay in reaching the deeper layers. These two patterns in combination with the larger dynamic range for SMOS indicate that the SMOS penetration depth would be less than $5 \mathrm{~cm}$.

$<$ Insert Fig. 2 here>

Quantitatively, the results obtained for the comparison between SMOS L2 and in situ surface soil moisture (Fig. 3a) show an $\mathrm{R}$ ranging between 0.60 and 0.78 for each station and 0.78 for the area average (note that this $\mathrm{R}$ value corresponds to the correlation of the average soil moisture) and errors between 0.045 and $0.268 \mathrm{~m}^{3} \mathrm{~m}^{-3}$. The SMOS soil moisture exhibited a certain underestimation with respect to the ground observations, although it showed a quicker reactivity to rainfall events and dry-downs. This effect was detected in previous validation experiments in the same area (Sánchez et al. 2012; González-Zamora et al. 2015).

For the comparison between SMOS L2 and in situ soil moisture at 25 and $50 \mathrm{~cm}$ depth (Fig. 3b, c), the results are obviously worse. For the $25 \mathrm{~cm}$ (Fig. 3b), the R values for the 12 stations and the area average are lower $(R=0.71)$, and the RMSD and CRMSD $\left(0.070\right.$ and $0.053 \mathrm{~m}^{3} \mathrm{~m}^{-3}$, respectively) are higher than the values obtained at surface $\left(R=0.78, R M S D=0.068 \mathrm{~m}^{3} \mathrm{~m}^{-3}\right.$ and CRMSD $=0.047 \mathrm{~m}^{3} \mathrm{~m}^{-3}$ ). For the comparison between $\mathrm{SMOS}$ estimations and $\mathrm{SM}_{0-50 \mathrm{~cm}}$ (Fig. $3 \mathrm{~d}$ ), the results are very similar to those obtained at a depth of $25 \mathrm{~cm}\left(R=0.71, R M S D=0.085 \mathrm{~m}^{3} \mathrm{~m}^{-3}\right.$ and $c R M S D=0.053 \mathrm{~m}^{3} \mathrm{~m}^{-3}$ ). Not surprisingly, the worst results were obtained at a depth of 50 $\mathrm{cm}$ (Fig. 3c, with $\mathrm{R}=0.59$, RMSD $=0.111 \mathrm{~m}^{3} \mathrm{~m}^{-3}$ and $c R M S D=0.061 \mathrm{~m}^{3} \mathrm{~m}^{-3}$ ), because we are comparing soil layers of very different depths. The deeper the in situ soil moisture measurement, the worse the agreement with the surface satellite observations. The results of the bias in all depths are positive excepting in few stations, showing underestimation, in agreement with the previous results in Fig. 2.

$<$ Insert Fig. 3 here $>$

\subsection{Toptimal estimation}


Even if a reasonable relationship were found between the $L 2$ surface soil moisture product and the water content at deep layers, it is necessary to go further to obtain a good estimate of the water stored in the root zone. Thus, the model proposed by Wagner et al. (1999) and improved by Albergel et al. (2008) using the SWI as a surrogate of the RZSM was tested. As a given example, Figure 4 illustrates the time evolution of the soil moisture at $25 \mathrm{~cm}$ depth from the ground measurements at the N9 station together with the SWI results for 8, 50 and 100 days of the $T$ parameter. This particular case, which is representative of the ground observations, gave some insights on the use of the proposed statistics for the $T_{\text {opt }}$ estimation. It can be seen that as the $T$ parameter increased, the time series curve became smoother. Hence, the correlation coefficient, which reflects the similarity of the time series, may seem appropriate to discriminate the $T_{\text {opt }}$. Indeed, in Figure 4, the smaller value of $T$ for calculating SWI ( $T=8$ days) better defines the in situ evolution of soil moisture at the shallower layers ( 25 $\mathrm{cm})$.

\title{
$<$ Insert Fig. 4 here>
}

$T_{\text {opt }}$ is discriminated using different metrics from the comparison between the in situ soil moisture at different depths and the SWI calculated with T ranging from 1 to 120 days. Tables 2-4 show the different $T_{\text {opt }}$ obtained for each method at each station and different depths, as well as for the area average. T increased as the depth increased (Tables 2, 3), which is in agreement with the model assumptions of the SWI and the results obtained in former studies (Albergel et al. 2008; Brocca et al. 2010a; Paulik et al. 2014). However, $T_{\text {opt }}$ based in the $\mathrm{R}$ for $0-50 \mathrm{~cm}$ (Table 4) showed similar results to those obtained for $25 \mathrm{~cm}$ (Table 2), in line with the previous comparison between SMOS estimations and in situ soil moisture measurements. A feasible explanation for this closeness is that the weighted average for the 0 $50 \mathrm{~cm}$ estimation (1) gave more weight to the top soil layers $(0$ and $25 \mathrm{~cm})$.

\author{
$<$ Insert Table 2 here $>$ \\ $<$ Insert Table 3 here> \\ $<$ Insert Table 4 here $>$
}

Regarding the statistics used, the range of $T_{\text {opt }}$ is lower when using $R$ as the decision metric. Note that the $T_{\text {opt }}$ obtained for the NS score was similar to that obtained for the RMSD in most of the stations and for the area average.

$\mathrm{T}_{\text {opt }}$ for the $25 \mathrm{~cm}$ depth (Table 2) based in $\mathrm{R}$ ranged between 1 and 17 for each station and $\mathrm{T}_{\mathrm{opt}}$ based on the NS score is between 1 and 82; the rest of $T_{\text {opt }}$ based on the other statistics ranged between 1 and 120, without suggesting an ideal T. For the $50 \mathrm{~cm}$ depth (Table 3), the $T_{\text {opt }}$ value based in the R and NS score increases when the in situ depth observations increase. For RMSD, cRMSD and bias, there are stations where the $T_{\text {opt }}$ remains identical for all depths, whereas in other stations $T_{\text {opt }}$ is greater for $25 \mathrm{~cm}$ (Table 2) than for $50 \mathrm{~cm}$ (Table 3), which leads to an unrealistic result.

Figure 5 depicts the shape and evolution of the metrics for T varying from 1 to 120 days. Using $R$ to obtain the optimal T (Fig. 5a), similar curve shapes were obtained for all stations, with a similar range of $R$, suggesting $R$ as a consistent metric for obtaining the $T_{\text {opt }}$. For most applications it is probably more important to capture the correct temporal pattern of the RZSM rather than the absolute value, making the correlation (Fig. 5a) and NS (Fig. 5e) the most appropriate metrics. In contrast, the rest of the metrics had a high level of scattering.

The lack of definition when using RMSD and CRMSD could be explained because in most stations, the range between the maximum and minimum values of RMSD and CRMSD is very small ( 0.015) making the choice of $\mathrm{T}_{\text {opt }}$ very difficult (Fig 5b, c). The same reasoning can be 
applied to the $T_{\text {opt }}$ obtained through the bias as a control metric, where the $T_{\text {opt }}$ had no distinguishable values in most stations for all depths (Table 2-4, Fig. 5d).

\section{$<$ Insert Fig. 5 here $>$}

The difficulty of defining an optimal $T$ is even more marked when using the bias as the reference metric, where the use of different Ts leads to an invariable bias until the fourth decimal (Fig. $5 \mathrm{~d}$ ). It can be inferred that the differences (expressed by a single value, the bias) between the estimated SWI and the observed soil moisture are negligible, probably due to a balance in the negative and positive values resulting in a bias close to zero in all cases. Therefore, the RMSD, CRMSD and bias were considered unsuitable for calculating the $T_{\text {opt }}$, and therefore they are discarded for further analysis.

The results showed that for a number of stations $T_{\text {opt }}$ is very large. As $T_{\text {opt }}$ gets larger the SWI time series becomes more and more representative of the RZSM seasonal cycle, but it likely does not capture possible short term variations in the RZSM. With this aim, a test using anomalies instead of SWI and in situ soil moisture measurements was done (results not shown), applying the standard deviation and mean of the five-year records for each day. The new $T_{\text {opt }}$ calculated with these anomaly series resulted very different than those obtained with the original series. Nevertheless, the resulting correlations between the anomalies of soil moisture and SWI time series are equally robust than the calculated with both original time series, reinforcing the strength of the method. However, the calculation of anomalies using means and standard deviations calculated with only five data seemed not statistically reliable, and more data are required to draw conclusive results.

In the study of de Lange et al. (2008), $\mathrm{T}_{\text {opt }}$ was estimated for each soil texture type using the RMSD method and comparing the modeled soil moisture data at different depths with the ERS scatterometer-derived SWI. Then, they calculated the SWI for each soil texture type, with its corresponding $\mathrm{T}_{\mathrm{opt}}$ and another conventional $\mathrm{T}_{\mathrm{opt}}=20$ days, and found that there were no differences in the estimation of the RZSM whether using one specific $T_{\text {opt }}$ or a generic $T_{\text {opt }}$, in line with the results obtained in other studies (Albergel et al. 2008; Paulik et al. 2014).

Albergel et al. (2009) found $T_{\text {opt }}=14$ days for $30 \mathrm{~cm}$ using ASCAT soil moisture data. Brocca et al. (2010a) found a $T_{\text {opt }}=19.5$ days for a layer depth of $10 \mathrm{~cm}, 23$ days for $20 \mathrm{~cm}$ and 29 days for $40 \mathrm{~cm}$, using also ASCAT soil moisture. Those results for $T_{\text {opt }}$ are higher than the results obtained in the present study using R (4 days for $25 \mathrm{~cm}$ and 21 days for $50 \mathrm{~cm}$ ). Moreover, in a previous study over the same area with ERS data, Ceballos et al. (2005) also obtained a higher $\mathrm{T}_{\text {opt }}$ value (40 days) for the $0-25 \mathrm{~cm}$ depth. In this case, the discrepancy could be explained by the different time interval of the in situ measurements, being daily in the current research and fortnightly in the former, and for the different soil moisture probes used.

Using modeled soil moisture data, Brocca et al. (2010b) obtained $\mathrm{T}_{\text {opt }}$ values ranging between 30 and 90 days with ASCAT soil moisture and the correlation coefficient as $\mathrm{T}_{\text {opt }}$ estimator, for a layer depth of 1-1.5 m. Pellarin et al. (2006) used ERS soil moisture data to obtain a $\mathrm{T}_{\text {opt }}=39$ days, both higher than the $T_{\text {opt }}$ obtained in this research. On the contrary, other studies where in situ soil moisture at different depths was used for estimating $T_{\text {opt }}$, such as those of Albergel et al. (2008) and Ford et al. (2014), found low values for the $T_{\text {opt }}$ using the NS statistic. As in situ data are less noisy than satellite retrievals it is also not surprising that T values are lower (Su et al. 2015). In particular, Albergel et al. (2008) found a $T_{\text {opt }}=6$ days for a layer of $30 \mathrm{~cm}$ in SMOSMANIA and SMOSREX networks in France, and Ford et al. (2014) found a $T_{\text {opt }}=8$ days and $\mathrm{T}_{\mathrm{opt}}=9$ days in two different study areas in the Oklahoma Mesonet and Nebraska Automated Weather Data Network in the USA, similar to the $T_{\text {opt }}$ values shown in this research.

Paulik et al. (2014) used different T values with the ASCAT surface soil moisture data to obtain SWI at different depths, but they did not find a clear $\mathrm{T}_{\text {opt }}$ value, and their conclusion is that $T_{\text {opt }}$ generally increases with the depth of the observed soil. 
Brocca et al. (2010a) argued that the high variability of $\mathrm{T}_{\text {opt }}$ obtained in the different studies could be due to the different lengths of the data series. However, the period used to calculate $\mathrm{T}_{\text {opt }}$ in our study and the study presented by Albergel et al. (2008) was very different, even though the retrieved $\mathrm{T}_{\text {opt }}$ was similar for all of them. Hence, one can suspect that the length of the series is not so critical.

A wide range of factors that are poorly understood seemed to influence the $T_{\text {opt }}$ retrieval. Theoretically, the soil type and the climate would be crucial factors, however, in several studies it was shown that the type of soil has no influence and the climate influence is uncertain (Paulik et al. 2014). Regarding the database used for calculating $T_{\text {opt, }}$, the use of in situ soil moisture values or remote-sensed values could lead to large differences in the calculated value of $\mathrm{T}$, being more important than the length of the series.

\subsection{Soil Water Index estimated from SMOS}

The $S W I_{S M O S}$ was calculated from SMOS L2 and the $T_{\text {opt }}$ obtained in the previous subsection. As a given example, Fig. 6 show the SWI results for three stations with very different $T_{\text {opt }}$ at 25 and $50 \mathrm{~cm}$ depth. At $25 \mathrm{~cm}$, the $T_{\text {opt }}$ is very low for $F 6$ ( $T_{\text {opt }}=1$, Fig. 6a), intermediate for $N 9$ ( $T_{\text {opt }}=8$, Fig. 6e) and very high for $M 9$ ( $T_{\text {opt }}=1$, Fig. $\left.6 c\right)$. In these figures it is noticeable how the variability of SWI decreases as the $\mathrm{T}_{\text {opt }}$ increases, i.e., $\mathrm{F} 6$ is more variable than $\mathrm{N} 9$, which in turn is more variable than M9. Same behavior was found at $50 \mathrm{~cm}$ depth, where $N 9$ ( $T_{\text {opt }}=25$, Fig. $6 \mathrm{f})$ is more variable than $\mathrm{M9}\left(\mathrm{T}_{\mathrm{opt}}=43\right.$, Fig. $\left.6 \mathrm{~d}\right)$ which in turn is more variable than $\mathrm{F} 6\left(\mathrm{~T}_{\mathrm{opt}}=71\right.$, Fig. 6b). In summary, for both 25 and $50 \mathrm{~cm}$ depth, it can be seen as for low $T_{\text {opt }}$, the variability of the SWI was higher than for large $T_{\text {opt }}$, and for the same reason, the variability of SWI for 25 $\mathrm{cm}$ was higher than for $50 \mathrm{~cm}$, owing its smaller $T_{\text {opt }}$. The $S W I$ results well reproduce the expected behavior of soil moisture at the root zone, and in all cases, the temporal cycle is well reproduced.

$<$ Insert Fig. 6 here $>$

Figures 7a-c shows the results of the comparison between the soil moisture measurements at the different depths and the $S W_{S} I_{S M}$ using the $T_{\text {opt }}$ obtained by the R and the NS score. No large differences were found between stations in the results for all depths using the different $\mathrm{T}_{\text {opt. }}$. Only a few stations showed differences in correlations, but errors and bias remain in the same order of magnitude.

\section{$<$ Insert Fig. 7 here $>$}

Regarding the results obtained for the different depths, it was observed that errors were higher at $50 \mathrm{~cm}$ (Fig. 7b) than they were both at $25 \mathrm{~cm}$ (Fig. 7a) and 0-50 cm (Fig. 7c), although the correlation was similar. The bias was positive in 9 of the 12 stations for all depths, indicating that $\mathrm{SWI}_{\mathrm{SMOS}}$ underestimated the RZSM. Comparing these results with those obtained in Section 4.1, it was proven that the SWI improved the estimation of the RZSM as compared to the use of the single SMOS L2 as an estimator of RZSM. This improvement took place at $25 \mathrm{~cm}$ and $0-50 \mathrm{~cm}$, but mostly at a depth of $50 \mathrm{~cm}$, indicating that the $S W I$ is a better proxy of the RZSM than the use of only L2 surface soil moisture.

\section{$<$ Insert Fig. 8 here>}

In a recent work with SMOS data, Ford et al. (2014) showed similar results to those of the present study in two different areas in the USA, Oklahoma and Nebraska, even though not all stations had significant results, in contrast with the significant correlations found in the present study overall (Fig. 7). These authors, together with Albergel et al. (2008) found that 
although $T_{\text {opt }}$ varied strongly among stations in their studies, using the overall average $T_{\text {opt }}$ based on all stations did not result in a significant decrease of the SWI accuracy. In the current research, the area-average $T_{\text {opt }}$ was evaluated too, finding similar results to the results obtained using a $\mathrm{T}_{\mathrm{opt}}$ for each station, in line with those works. Fig. 8 showed that using the area-average $T_{\text {opt }}$ (obtained with R or NS) the correlations were similar to those obtained with an individual $T_{\text {opt }}$ for each station.

When the SWI is calculated with other remote-sensing sources of data, the results are within the same precision. For example, Ceballos et al. (2005) found higher correlation $(R=0.87)$ between the SWI derived from the ERS scatterometer and in situ observations over the same area. Additionally, Wagner et al. (2003) found similar results using multiple stations in Ukraine and Brocca et al. (2010a) with ASCAT-derived SWI and in situ soil moisture observations in Northern Italy.

\subsection{Plant Available Water}

As for the SWI results, Fig. 9 represents the PAW series for the same stations with $\mathrm{T}_{\text {opt }}$ low (F6 at $25 \mathrm{~cm}$, Fig. 9a and N9 at $50 \mathrm{~cm}$, Fig. 9h), intermediate ( $\mathrm{N} 9$ at $25 \mathrm{~cm}$, Fig. $9 \mathrm{~g}$ and M9 at $50 \mathrm{~cm}$, Fig. 9e) and high (M9 at $25 \mathrm{~cm}$, Fig. $9 \mathrm{~d}$ and F6 at $50 \mathrm{~cm}$, Fig. 9b). The time evolution of PAW $\mathrm{SMOs}$ agreed well with the PAW ${ }_{\text {Insitu }}$ and followed closely the dry-downs and wetting events. The values of $T_{\text {opt }}$ seem not to affect the agreement between both time series, PAW SMOs $_{\text {and }}$ PAW ${ }_{\text {Insitu, }}$ but the variability of PAW is similar to that of $T_{\text {opt }}$, being higher for low values.

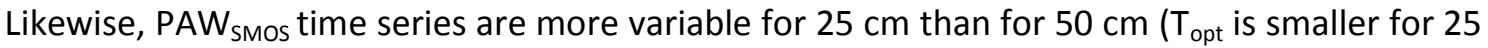
$\mathrm{cm}$ depth in all cases), matching the behavior of the PAW $_{\text {Insitu, }}$ which is also more fluctuating at $25 \mathrm{~cm}$. The in situ measurements respond to the different soil texture at the different layers (in general, more sandy in the upper soil layers) and the specific water dynamics in the soil layers (the deeper the layer, the steadier the water content). Thereby, the PAW approach agreed well with the ground observations.

Additionally, a slight time lag between PAW of autumn in 2010 and 2011), probably due to the faster SMOS response to rainfall events, observed in both 25 and $50 \mathrm{~cm}$ depths.

In the particular case of the showed stations (Fig. 9), the PAW Insitu values are higher than the PAW ${ }_{S M O S}$ values for both 25 and $50 \mathrm{~cm}$, which could be explained by the previously mentioned underestimation found for the SMOS surface soil moisture, which was corroborated in the scatterplot of both series (Fig. 9c, f, i). This underestimation was observed in 9 of the 12 stations used.

As for the soil moisture series (Fig. 2) from which the PAW is calculated, the PAW showed a marked seasonality according with the growing season of the plants. The PAW obtained at 25 $\mathrm{cm}$ has a maximum in the fall, which is maintained until the end of spring, while the minimum is reached in summer (except for some storm events as in 2011 or 2012). The water is accumulated in this period but not used by plants until the growing season, a period in which the PAW decreases accordingly. Overall, the curve of the PAW for $50 \mathrm{~cm}$ matches the rainfed vegetative cycle. In short, the PAW values obtained in the study area are consistent with the water-related behavior of the most common crops in this area.

$<$ Insert Fig. 9 here $>$

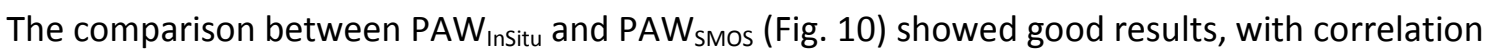
coefficients between 0.6 and 0.92 and errors lower than $0.05 \mathrm{~m}^{3} \mathrm{~m}^{-3}$ for $25 \mathrm{~cm}$. The $0-50 \mathrm{~cm}$ results are very similar to $25 \mathrm{~cm}$, in line with the results showed before. Better results are shown for the $50 \mathrm{~cm}$ depth, with higher correlation coefficients and lower errors than for 25 $\mathrm{cm}$ and $0-50 \mathrm{~cm}$ in most of the stations. This may be explained by the use of a higher $\mathrm{T}_{\text {opt }}$ for the $50 \mathrm{~cm}$ depth, resulting in a smoother curve of the PAW with less variability. Hence, smaller 
errors and higher correlations can be expected for $50 \mathrm{~cm}$ than for 25 or $0-50 \mathrm{~cm}$. Only H9, the station with the highest water content, increased the errors from $50 \mathrm{~cm}$ to $25 \mathrm{~cm}$. No remarkable differences were found when using $T_{\text {opt }}$ obtained from the $R$ and the NS methods (Fig 10a-c).

\section{$<$ Insert Fig. 10 here $>$}

The PAW values obtained here with SMOS were slightly smaller than those obtained using a similar methodology with other remote sensing sources (the active sensor ERS) in the same area, but using fortnightly Time Domain Reflectometry (TDR) measurements (Ceballos et al. 2005). The errors obtained there were the same magnitude order to the errors obtained here but the correlations resulted higher using SMOS soil moisture. In this line, Wagner et al. (2003) found also higher values of PAW using multiple stations in Ukraine with ERS.

\section{CONCLUSIONS}

PAW plays an important role in agriculture because it is an indicator of the soil storage capacity available for plant use. In this study, the PAW at different soil depths was obtained for the period between January 2010 and December 2014 through SMOS L2 surface soil moisture and the SWI model, which related the surface soil moisture to the root-zone soil moisture. For validating the method, in situ soil moisture measurements at different depths from REMEDHUS network (Spain) were used.

The time series comparison between SMOS surface soil moisture observations and in situ soil moisture measurements at the different depths showed good results in the shallower soil layers. As expected, the deeper the layer, the worse the agreement, thus, another proxy of the RZSM, such as the more complex SWI, was tested.

The use of the SWI for RZSM estimation involves the selection of a $T_{\text {opt. }}$. After the results, the selection of the $T_{\text {opt }}$ based on the RMSD and CRMSD metrics should be dismissed, because the range between the maximum and minimum of these metrics is small, making the selection difficult or even impossible. This caveat is much clearer in the selection of the $T_{\text {opt }}$ based on the bias. In this case, the bias is invariable for all values of T considered, making it impossible to decide on a given $T_{\text {opt }}$. On the other hand, the best metrics for selecting the $T_{\text {opt }}$ resulted from the $R$ and the NS scores. In light of the results obtained for both $T_{\text {opt }}$ with the SMOS L2 soil moisture product, achieving values of $R=0.88$ and errors $=0.03 \mathrm{~m}^{3} \mathrm{~m}^{-3}$ for $25 \mathrm{~cm}$ and $\mathrm{R}=0.81$ and errors $=0.035 \mathrm{~m}^{3} \mathrm{~m}^{-3}$ for $50 \mathrm{~cm}$, the use of the SWI seemed appropriate for the RZSM estimation. These results are in line with previous research where soil moisture data from other microwave satellites were used.

It can be concluded that the use of SMOS data with the methodology proposed in this research, integrating the SMOS L2 surface soil moisture in the SWI, led to a reasonably good estimation of the ground-based PAW. The similarity of PAW Insitu $_{\text {and }}$ PAW SMOS $_{\text {is notable, with }}$ high correlations $(R>0.65)$ and low errors (RMSD and $\left.c R M S D<0.05 \mathrm{~m}^{3} \mathrm{~m}^{-3}\right)$, providing a realistic description of the water content availability for the plants under study. Despite the low depth of the soil layer explored by the SMOS satellite, the SWI and PAW estimates have good agreement with in situ measurements, which are even better at deep layers than superficial ones. Although good results have been obtained, this study is located into a specific region and, therefore, the findings cannot be directly generalized. The results are encouraging but it is only a first step and much more work has to be done. In this research, soil properties measured at the laboratory were used, but these properties are not worldwide available. However, the number of soil moisture networks is increasing as well as the number of soil moisture stations that report soil properties around the world. In those places where reliable soil properties databases are not available, one option is using soil texture databases together with pedotransfer functions to obtain soil water parameters. The methodology used in this 
work should be tested under a wide range of soil characteristics and climate conditions, but the results obtained suggest that this new SMOS-derived product could be very useful for many future applications.

\section{ACKNOWLEDGMENTS}

This study was supported by the Spanish Ministry of Economy and Competitiveness (Project AYA2012-39356-C05-05 and ESP2015-67549-C3-3-R), Castilla y León Region Government (SA007U16) and the European Regional Development Fund (ERDF). The authors acknowledge the European Space Agency (Project AO-3230) for providing the SMOS data. The authors thank the anonymous reviewers for their valuable and useful suggestions that clearly improved the paper.

\section{REFERENCES}

Albergel, C., Rüdiger, C., Pellarin, T., Calvet, J.-C., Fritz, N., Froissard, F., Suquia, D., Petitpa, A., Piguet, B., \& Martin, E. (2008). From near-surface to root-zone soil moisture using an exponential filter: an assessment of the method based on in-situ observations and model simulations. Hydrology and Earth System Sciences, 12, 1323-1337

Albergel, C., Rüdiger, C., Carrer, D., Calvet, J.C., Fritz, N., Naeimi, V., Bartalis, Z., \& Hasenauer, S. (2009). An evaluation of ASCAT surface soil moisture products with in-situ observations in Southwestern France. Hydrol. Earth Syst. Sci., 13, 115-124

Albergel, C., de Rosnay, P., Gruhier, C., Muñoz-Sabater, J., Hasenauer, S., Isaksen, L., Kerr, Y., \& Wagner, W. (2012). Evaluation of remotely sensed and modelled soil moisture products using global ground-based in situ observations. Remote Sensing of Environment, 118, 215-226

Bartalis, Z., Wagner, W., Naeimi, V., Hasenauer, S., Scipal, K., Bonekamp, H., Figa, J., \& Anderson, C. (2007). Initial soil moisture retrievals from the METOP-A Advanced Scatterometer (ASCAT). Geophysical Research Letters, 34 (20), n/a-n/a

Bezerra, B.G., Santos, C.A.C.d., Silva, B.B.d., Perez-Marin, A.M., Bezerra, M.V.C., Bezerra, J.R.C., \& Rao, T.V.R. (2013). Estimation of soil moisture in the root-zone from remote sensing data. Revista Brasileira de Ciência do Solo, 37, 596-603

Brocca, L., Melone, F., Moramarco, T., Wagner, W., \& Hasenauer, S. (2010a). ASCAT soil wetness index validation through in situ and modeled soil moisture data in central Italy. Remote Sensing of Environment, 114, 2745-2755

Brocca, L., Melone, F., Moramarco, T., Wagner, W., Naeimi, V., Bartalis, Z., \& Hasenauer, S. (2010b). Improving runoff prediction through the assimilation of the ASCAT soil moisture product. Hydrol. Earth Syst. Sci., 14, 1881-1893

Brocca, L., Hasenauer, S., Lacava, T., Melone, F., Moramarco, T., Wagner, W., Dorigo, W., Matgen, P., Martínez-Fernández, J., Llorens, P., Latron, J., Martin, C., \& Bittelli, M. (2011). Soil moisture estimation through ASCAT and AMSR-E sensors: An intercomparison and validation study across Europe. Remote Sensing of Environment, 115, 3390-3408

Ceballos, A., Scipal, K., Wagner, W., \& Martínez-Fernández, J. (2005). Validation of ERS scatterometerderived soil moisture data in the central part of the Duero Basin, Spain. Hydrological Processes, 19, 1549-1566

Crow, W.T., Kustas, W.P., \& Prueger, J.H. (2008). Monitoring root-zone soil moisture through the assimilation of a thermal remote sensing-based soil moisture proxy into a water balance model. Remote Sensing of Environment, 112, 1268-1281

de Lange, R., Beck, R., van de Giesen, N., Friesen, J., De Wit, A., \& Wagner, W. (2008). ScatterometerDerived Soil Moisture Calibrated for Soil Texture With a One-Dimensional Water-Flow Model. IEEE Transactions on Geoscience and Remote Sensing, 46, 4041-4049

Delwart, S., Bouzinac, C., Wursteisen, P., Berger, M., Drinkwater, M., Martin-Neira, M., \& Kerr, Y.H. (2008). SMOS Validation and the COSMOS Campaigns. IEEE Transactions on Geoscience and Remote Sensing, 46, 695-704

Dorigo, W.A., Wagner, W., Hohensinn, R., Hahn, S., Paulik, C., Xaver, A., Gruber, A., Drusch, M., Meckelenburg, S., van Oevelen, P., Robock, A., \& Jackson, T. (2011). The International Soil Moisture 
Network: a data hosting facility for global in situ soil moisture measurements. Hydrology and Earth System Sciences, 15, 1675-1698

Entekhabi, D., Njoku, E.G., O'Neill, P.E., Kellogg, K.H., T., C.W., Edelstein, W.N., Entin, J.K., Goodman, S.D., Jackson, T.J., Johnson, J., Kimball, J., Piepmeyer, J.R., Koster, R.D., Martin, N., McDonald, K.C., Moghaddam, M., Moran, S., Reichle, R., Shi, J.C., Spencer, M.W., Thurman, S.W., Tsang, L., \& Van Zyl, J. (2010). The Soil Moisture Active Passive (SMAP) Mission. Proceedings of the IEEE, 98, 704-716

Ford, T.W., Harris, E., \& Quiring, S.M. (2014). Estimating root zone soil moisture using near-surface observations from SMOS. Hydrol. Earth Syst. Sci. (HESS), 18, 139-154

González-Zamora, Á., Sánchez, N., Martínez-Fernández, J., Gumuzzio, Á., Piles, M., \& Olmedo, E. (2015). Long-term SMOS soil moisture products: A comprehensive evaluation across scales and methods in the Duero Basin (Spain). Physics and Chemistry of the Earth, Parts A/B/C, 83-84, 123-136

Kerr, Y., Waldteufel, P., Wigneron, J.-P., Delwart, S., Cabot, F., Boutin, J., Escorihuela, M.-J., Font, J., Reul, N., Gruhier, C., Juglea, S., Drinkwater, M., Hahne, A., Martín-Neira, M., \& Mecklenburg, S. (2010). The SMOS Mission: New Tool for Monitoring Key Elements of the Global Water Cycle. Proceedings of the IEEE, 98, 666-687

Kerr, Y.H., Waldteufel, P., Richaume, P., Wigneron, J.P., Ferrazzoli, P., Mahmoodi, A., Al Bitar, A., Cabot, F., Gruhier, C., Juglea, S.E., Leroux, D., Mialon, A., \& Delwart, S. (2012). The SMOS soil moisture retrieval algorithm. IEEE Transactions on Geoscience and Remote Sensing, 50, 1384-1403

Koster, R.D., Reichle, R.H., De Lannoy, G.J., Liu, Q., Colliander, A., Conaty, A., Jackson, T. \& Kimball, J., 2015. Technical Report Series on Global Modeling and Data Assimilation. Volume 40; Soil Moisture Active Passive (SMAP) Project Assessment Report for the Beta-Release L4_SM Data Product

Laiolo, P., Gabellani, S., Campo, L., Silvestro, F., Delogu, F., Rudari, R., Pulvirenti, L., Boni, G., Fascetti, F., Pierdicca, N., Crapolicchio, R., Hasenauer, S., \& Puca, S. (2015). Impact of different satellite soil moisture products on the predictions of a continuous distributed hydrological model. International Journal of Applied Earth Observation and Geoinformation, 48, 131-145

Legates, D.R., Mahmood, R., Levia, D.F., DeLiberty, T.L., Quiring, S.M., Houser, C., \& Nelson, F.E. (2011). Soil moisture: A central and unifying theme in physical geography. Progress in Physical Geography, 35, 65-86

Liu, S., Roberts, D.A., Chadwick, O.A., \& Still, C.J. (2012). Spectral responses to plant available soil moisture in a Californian grassland. International Journal of Applied Earth Observation and Geoinformation, 19, 31-44

Mahmood, R., \& Hubbard, K.G. (2007). Relationship between soil moisture of near surface and multiple depths of the root zone under heterogeneous land uses and varying hydroclimatic conditions. Hydrological Processes, 21, 3449-3462

Martínez-Fernández, J., González-Zamora, A., Sánchez, N., \& Gumuzzio, A. (2015). A soil water based index as a suitable agricultural drought indicator. Journal of Hydrology, 522, 265-273

Njoku, E.G., Jackson, T.J., Lakshmi, V., Chan, T.K., \& Nghiem, S.V. (2003). Soil moisture retrieval from AMSR-E. IEEE Transactions on Geoscience and Remote Sensing, 41, 215-229

Ochsner, T.E., Cosh, M.H., Cuenca, R.H., Dorigo, W.A., Draper, C.S., Hagimoto, Y., Kerr, Y.H., Larson, K.M., Njoku, E.G., Small, E.E., \& Zreda, M. (2013). State of the art in large-scale soil moisture monitoring. Soil Science Society of America Journal, 77, 1888-1919

Paulik, C., Dorigo, W., Wagner, W., \& Kidd, R. (2014). Validation of the ASCAT soil water index using in situ data from the International Soil moisture network. International Journal of Applied Earth Observation and Geoinformation, 30, 1-8

Pellarin, T., Calvet, J.-C., \& Wagner, W. (2006). Evaluation of ERS scatterometer soil moisture products over a half-degree region in southwestern France. Geophysical Research Letters, 33, n/a-n/a

Pietola, L., \& Alakukku, L. (2005). Root growth dynamics and biomass input by Nordic annual field crops. Agriculture, Ecosystems \& Environment, 108, 135-144

Piles, M., Sánchez, N., Vall-llossera, M., Camps, A., Martínez-Fernández, J., Martínez, J., \& GonzálezGambau, V., (2014). "A dowscaling approach for SMOS land observations: long-term evaluation of high resolution soil moisture maps over the Iberian Peninsula," IEEE Journal of Selected Topics in Applied Earth Observations and Remote Sensing, vol. 7, pp. 3845-3857

Rebel, K.T., de Jeu, R.A.M., Ciais, P., Viovy, N., Piao, S.L., Kiely, G., \& Dolman, A.J. (2012). A global analysis of soil moisture derived from satellite observations and a land surface model. Hydrol. Earth Syst. Sci., 16, 833-847

Renzullo, L.J., van Dijk, A.I.J.M., Perraud, J.M., Collins, D., Henderson, B., Jin, H., Smith, A.B., \& McJannet, D.L. (2014). Continental satellite soil moisture data assimilation improves root-zone moisture analysis for water resources assessment. Journal of Hydrology, 519, Part D, 2747-2762 
Rienecker, M.M., Suarez, M.J., Gelaro, R., Todling, R., Bacmeister, J., Liu, E., Bosilovich, M.G., Schubert, S.D., Takacs, L., Kim, G.-K., Bloom, S., Chen, J., Collins, D., Conaty, A., da Silva, A., Gu, W., Joiner, J., Koster, R.D., Lucchesi, R., Molod, A., Owens, T., Pawson, S., Pegion, P., Redder, C.R., Reichle, R., Robertson, F.R., Ruddick, A.G., Sienkiewicz, M., \& Woollen, J. (2011). MERRA: NASA's Modern-Era Retrospective Analysis for Research and Applications. Journal of Climate, 24, 3624-3648

Sabater, J.M., Jarlan, L., Calvet, J.-C., Bouyssel, F., \& De Rosnay, P. (2007). From Near-Surface to RootZone Soil Moisture Using Different Assimilation Techniques. Journal of Hydrometeorology, 8, 194-206 Sánchez, N., Martinez-Fernandez, J., Scaini, A., \& Perez-Gutierrez, C. (2012). Validation of the SMOS L2 Soil Moisture Data in the REMEDHUS Network (Spain). IEEE Transactions on Geoscience and Remote Sensing, 50, 1602-1611

Santos, W.J.R., Silva, B.M., Oliveira, G.C., Volpato, M.M.L., Lima, J.M., Curi, N., \& Marques, J.J. (2014). Soil moisture in the root zone and its relation to plant vigor assessed by remote sensing at management scale. Geoderma, 221-222, 91-95

Schnur, M.T., Xie, H., \& Wang, X. (2010). Estimating root zone soil moisture at distant sites using MODIS NDVI and EVI in a semi-arid region of southwestern USA. Ecological Informatics, 5, 400-409

Su, C.-H., Narsey, S.Y., Gruber, A., Xaver, A., Chung, D., Ryu, D., \& Wagner, W. (2015). Evaluation of post-retrieval de-noising of active and passive microwave satellite soil moisture. Remote Sensing of Environment, 163, 127-139

van Genuchten, M.T. (1980). A Closed-form Equation for Predicting the Hydraulic Conductivity of Unsaturated Soils. Soil Science Society of America Journal, 44, 892-898

Wagner, W., Lemoine, G., \& Rott, H. (1999). A Method for Estimating Soil Moisture from ERS Scatterometer and Soil Data. Remote Sensing of Environment, 70, 191-207

Wagner, W., Scipal, K., Pathe, C., Gerten, D., Lucht, W., \& Rudolf, B. (2003). Evaluation of the agreement between the first global remotely sensed soil moisture data with model and precipitation data. Journal of Geophysical Research: Atmospheres, 108(D19), n/a-n/a

Wang, X., Xie, H., Guan, H., \& Zhou, X. (2007). Different responses of MODIS-derived NDVI to rootzone soil moisture in semi-arid and humid regions. Journal of Hydrology, 340, 12-24

Zaman, B., \& McKee, M. (2014). Spatio-Temporal Prediction of Root Zone Soil Moisture Using Multivariate Relevance Vector Machines. Open Journal of Modern Hydrology, 04(03), 11 


\section{Figure Captions}

Fig. 1. Location of the stations included in the study.

Fig. 2. SMOS and in situ soil moisture measurements (area-average) at the different depths used in the study. Precipitation data is also shown.

Fig. 3. Results of the comparison between the time series of each in situ station with its corresponding SMOS L2 DGG at a) surface, b) $25 \mathrm{~cm}$ depth, c) $50 \mathrm{~cm}$ depth and d) 0-50 cm depth. Area-averaged results are also shown. All the stations are significant at 0.01 confidence level.

Fig. 4. In situ soil moisture measurements and SWI time series from N9 station calculated with different $\mathrm{T}(8,50$ and 100 days) at $25 \mathrm{~cm}$ depth.

Fig. 5. T parameter following the correlation coefficient (a), RMSD (b), cRMSD (c), Bias (d) and NS score (e) after the comparison between SWI Insitu and in situ soil moisture measurements at $25 \mathrm{~cm}$ depth. $\mathrm{O} 7$ station was removed in NS plot because results were out of range.

Fig. 6. Results of the comparison between the time series of the $S W I_{S M O S}$ (using $T_{\text {opt }}$ obtained with R and NS score) with the in situ measurement stations at a) $25 \mathrm{~cm}$ depth, b) $50 \mathrm{~cm}$ depth and c) $0-50 \mathrm{~cm}$ depth. All the stations are significant at 0.01 confidence level.

Fig. 7. SWI time series and in situ soil moisture measurements from F6 (a, b), M9 (c, d) and N9 $(e, f)$ stations at 25 and $50 \mathrm{~cm}$ depth, respectively. Precipitation data is also shown.

Fig. 8. Boxplots of correlations between in situ soil moisture measurements and SWI calculated for individual stations and area-averaged at each depth. $R$ Station corresponds to the $T_{\text {opt }}$ calculated with $\mathrm{R}$ for individual stations, $\mathrm{R}$ Average corresponds to the $\mathrm{T}_{\text {opt }}$ calculated with $\mathrm{R}$ for area-averaged, NS Station corresponds to the $T_{\text {opt }}$ calculated with NS for individual stations and NS Average corresponds to the $\mathrm{T}_{\text {opt }}$ calculated with NS for area-averaged.

Fig. 9. PAW time series from $F 6(a, b), M 9(d, e)$ and $N 9$ station $(g, h)$ calculated with $T_{\text {opt }}$ obtained by correlation coefficient for $S W I_{S M O S}$ and $S W I_{I n S i t u}$ at $25 \mathrm{~cm}$ depth and $50 \mathrm{~cm}$ depth, and scatterplot for the comparison between PAW Insitu and PAW $_{S M O S}(c, f, i)$, respectively. Precipitation data is also shown.

Fig. 10. Results of the comparison between the time series of the PAW ${ }_{S M O S}$ and PAW $W_{\text {Insitu, with }}$ $\mathrm{T}_{\text {opt }}$ obtained with R and NS score at a) $25 \mathrm{~cm}$ depth, b) $50 \mathrm{~cm}$ depth and c) 0-50 cm depth. All the stations are significant at 0.01 confidence level. 


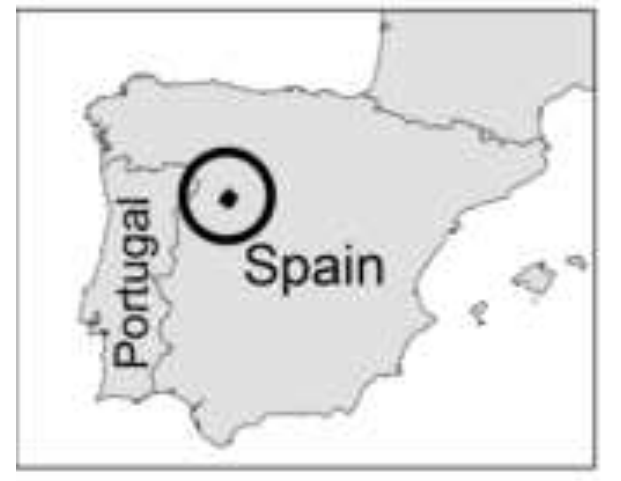

REMEDHUS NETWORK

$\Delta$ Soil moisture station
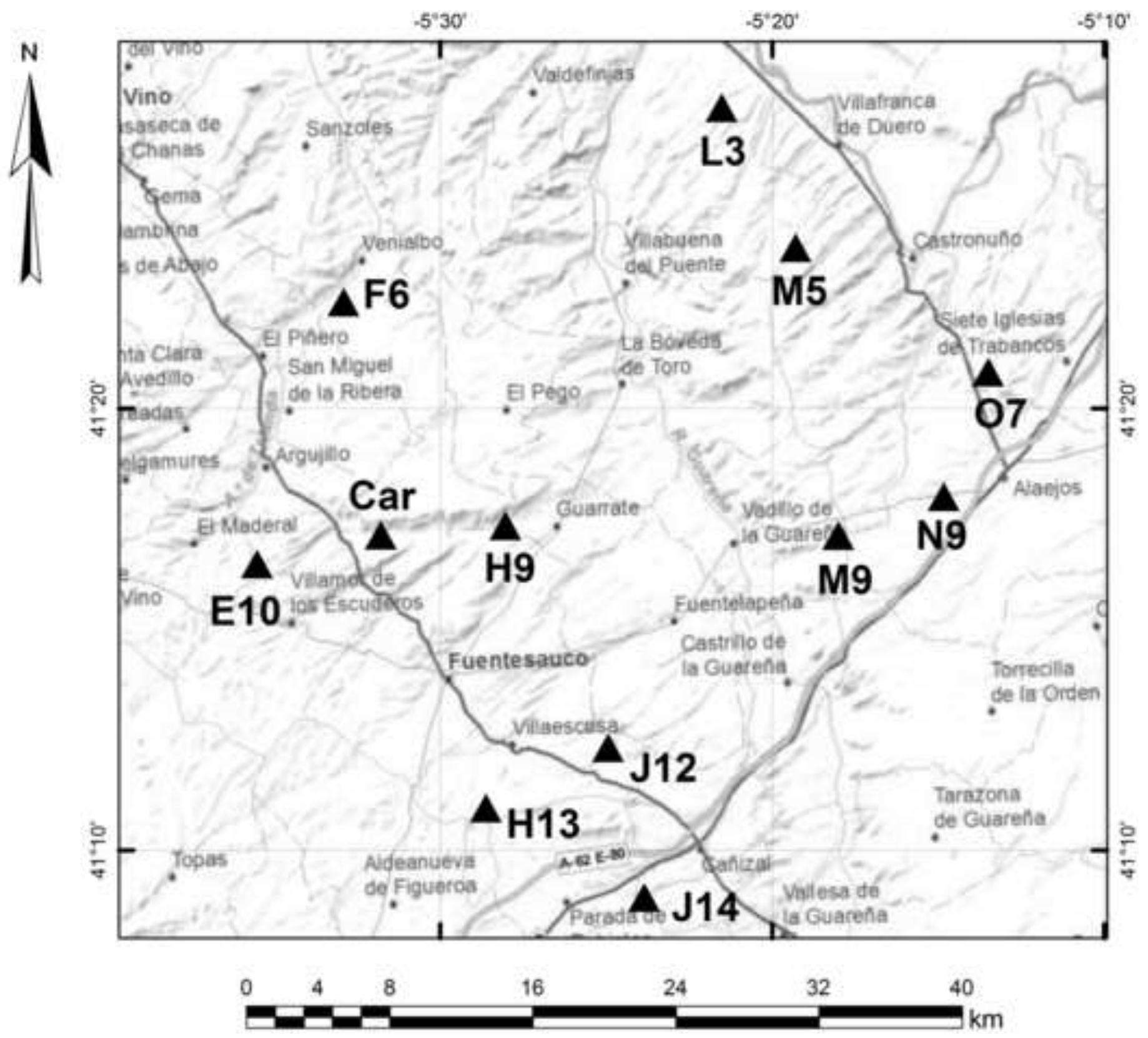


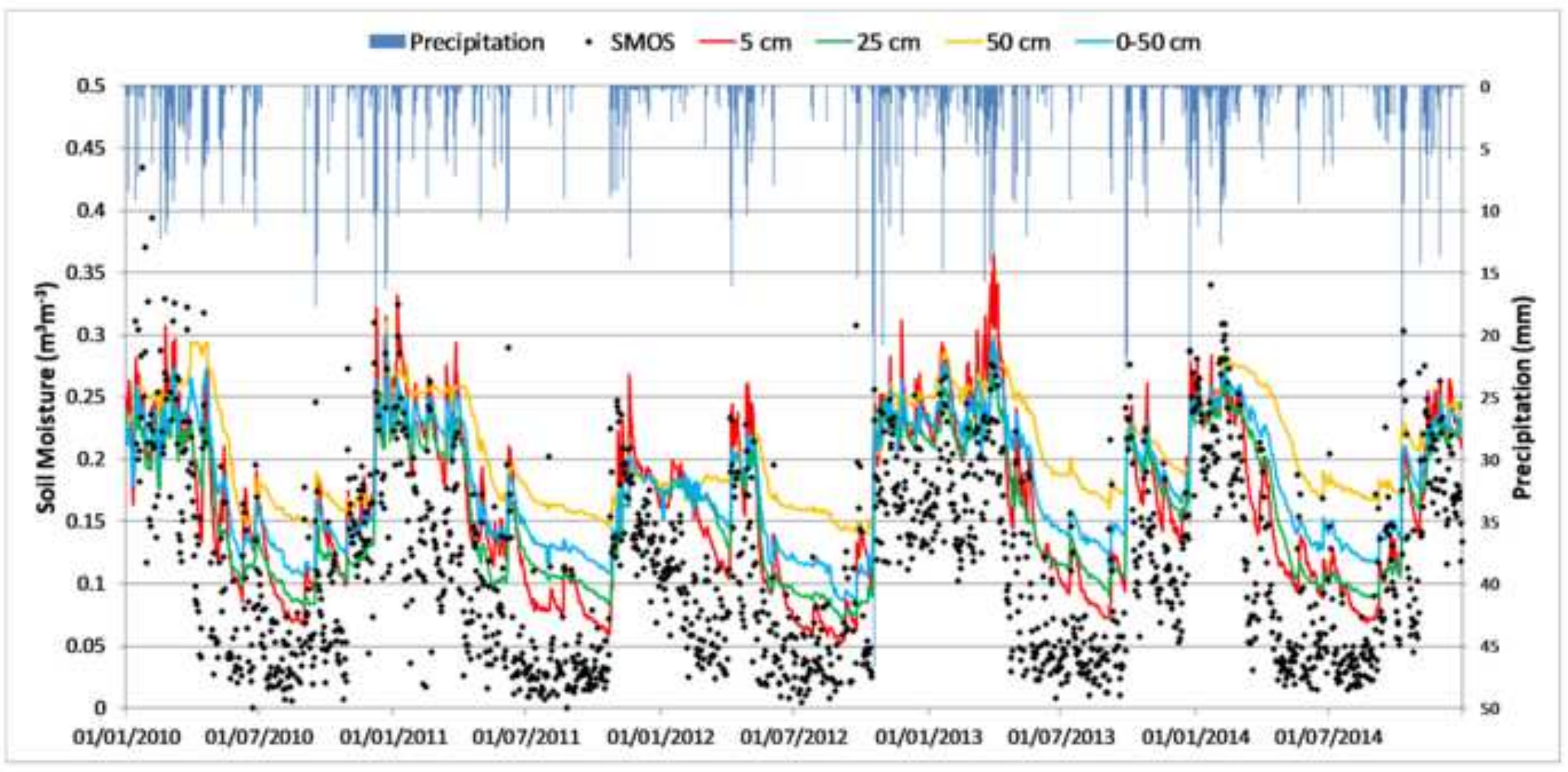



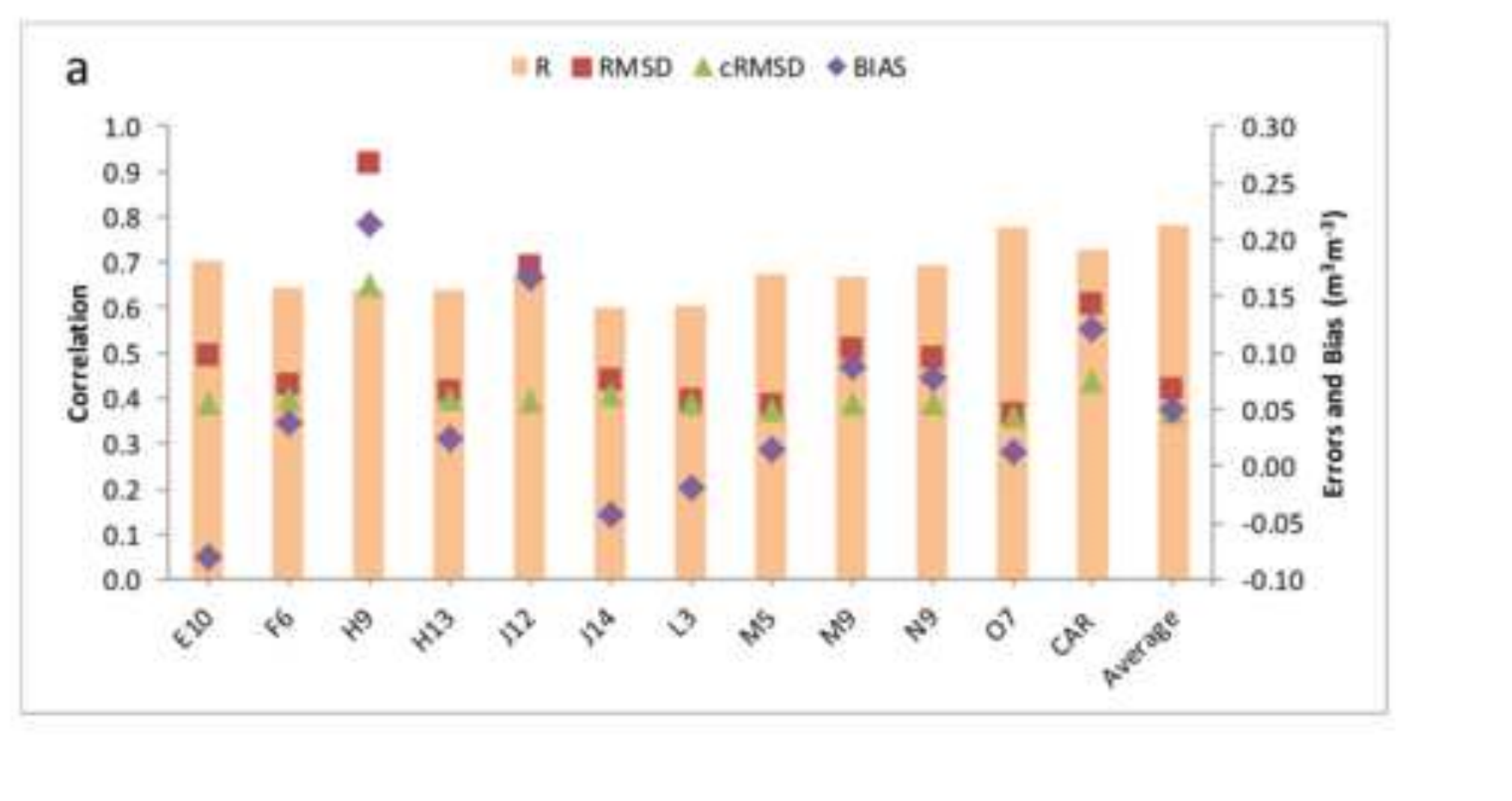

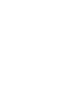
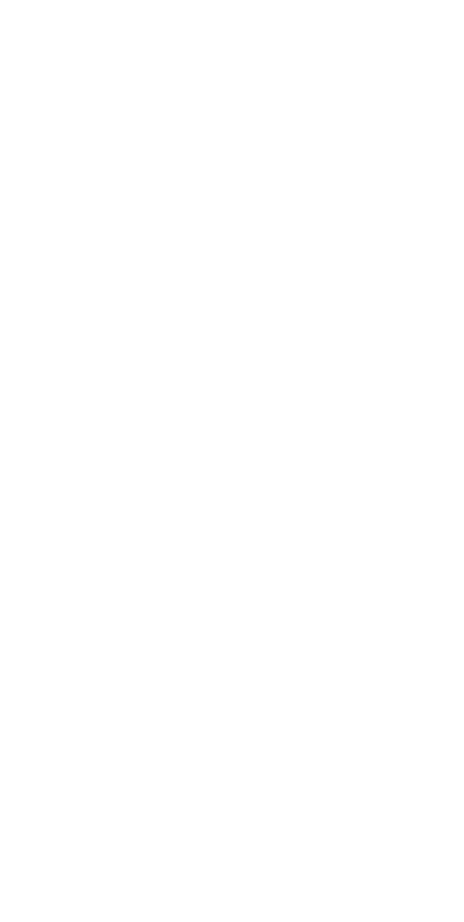

. 


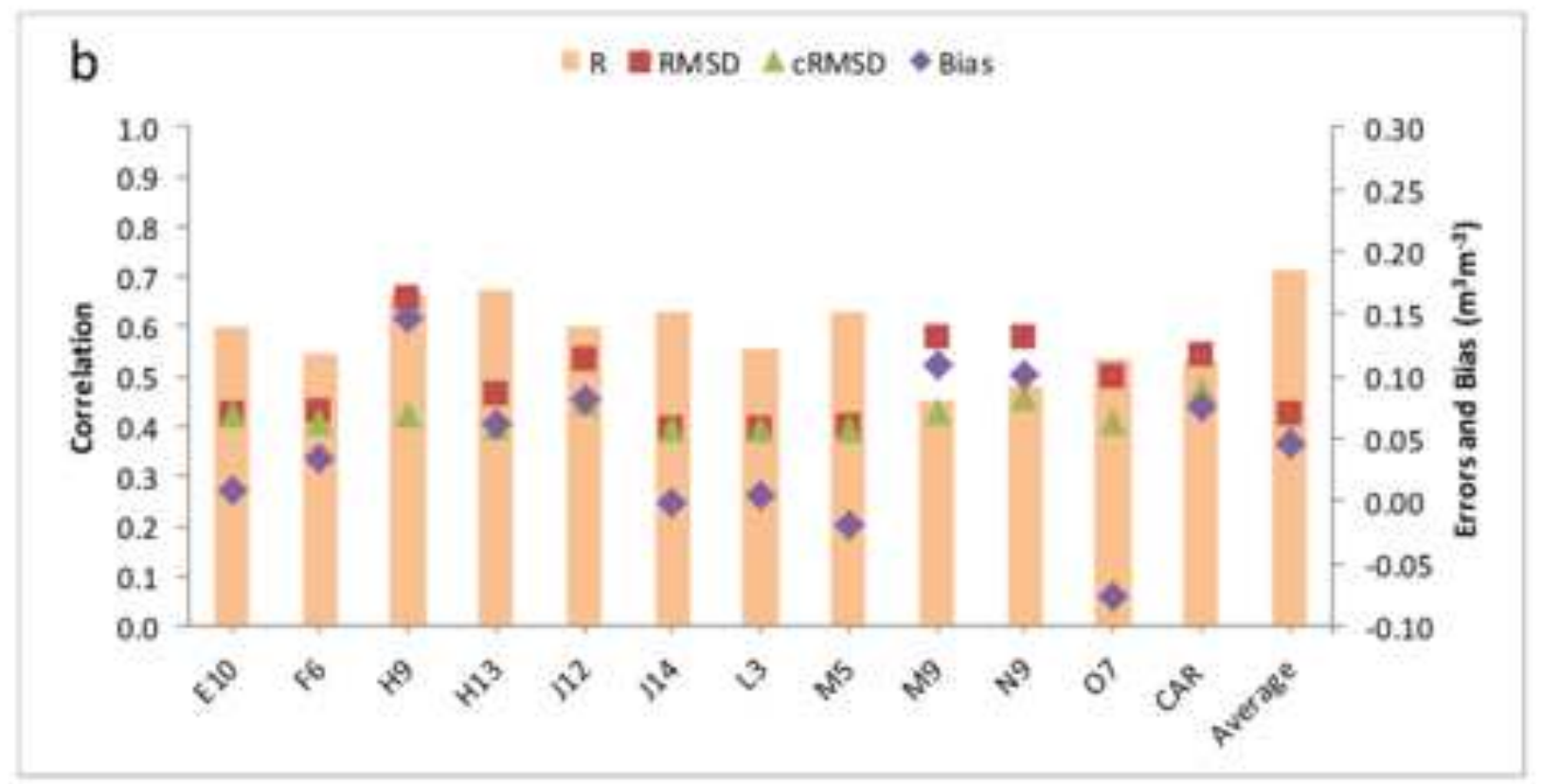



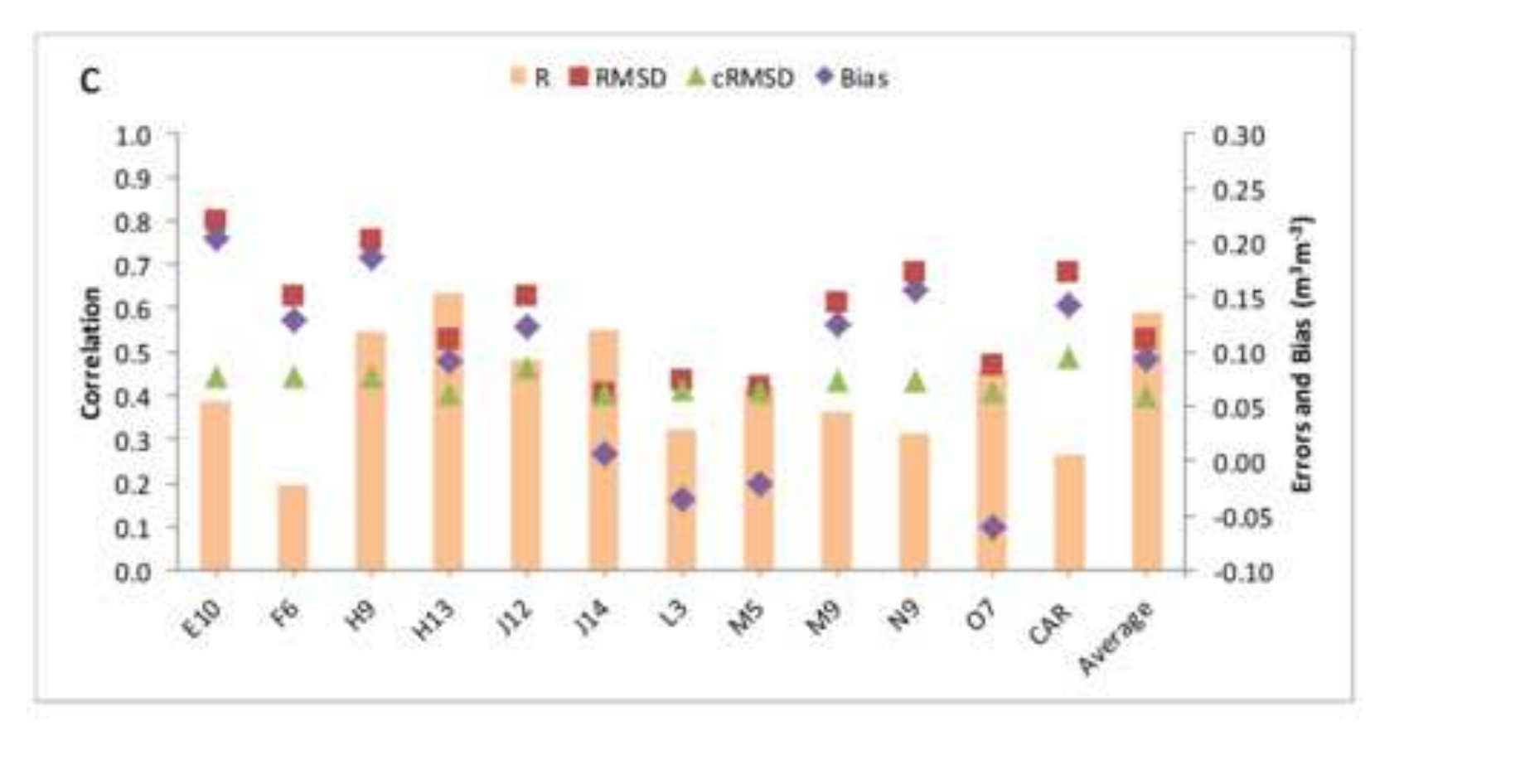


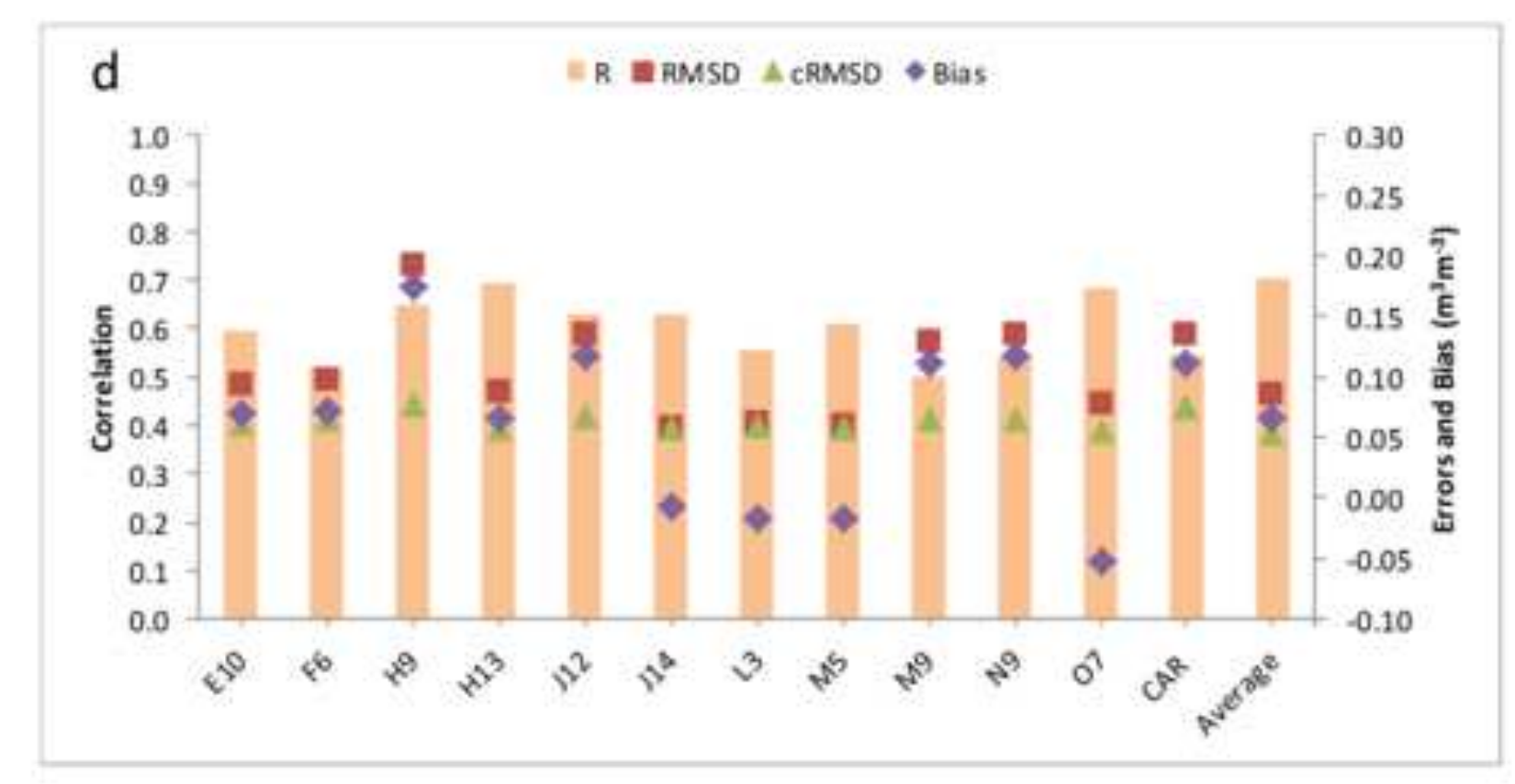




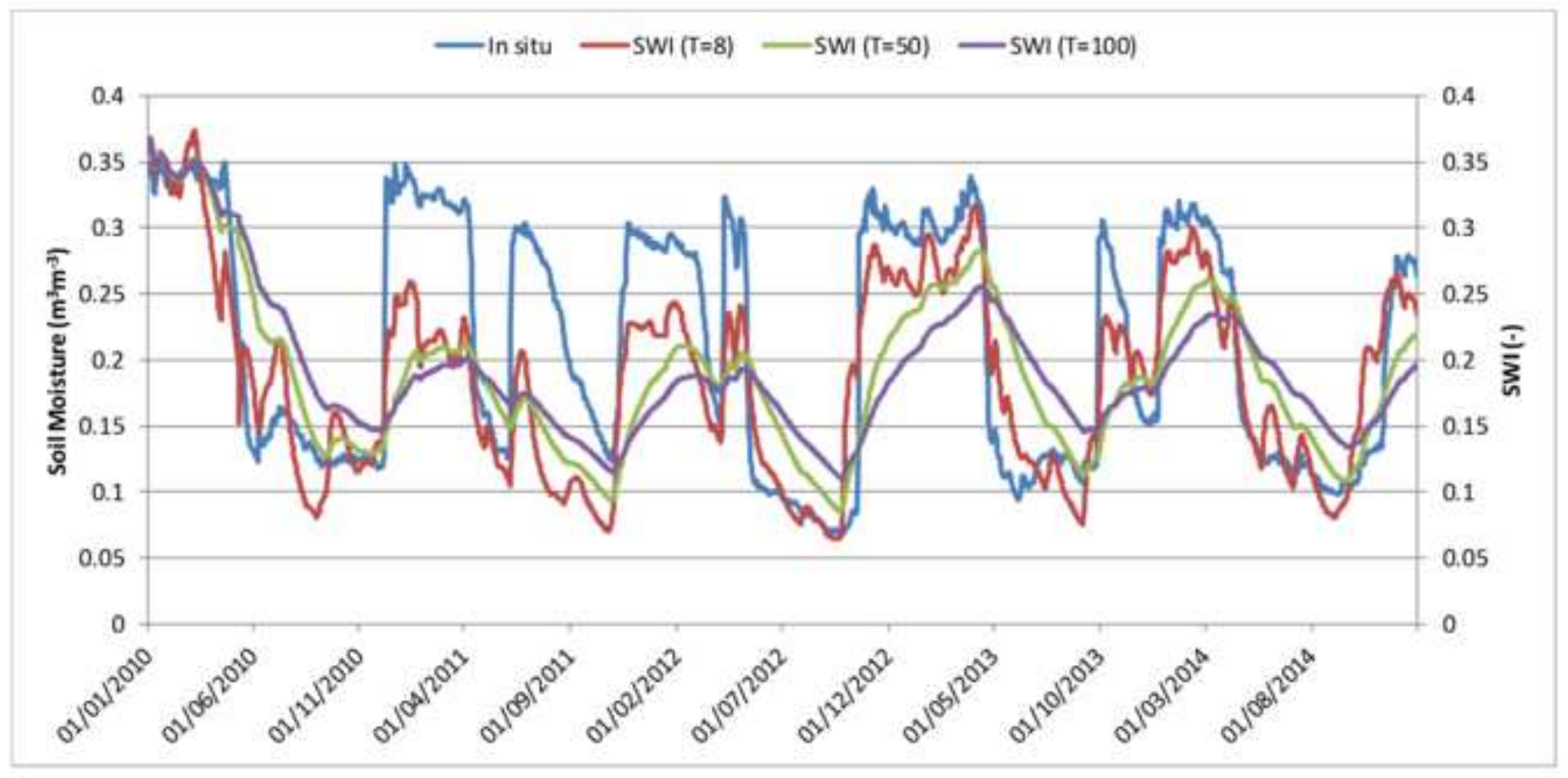




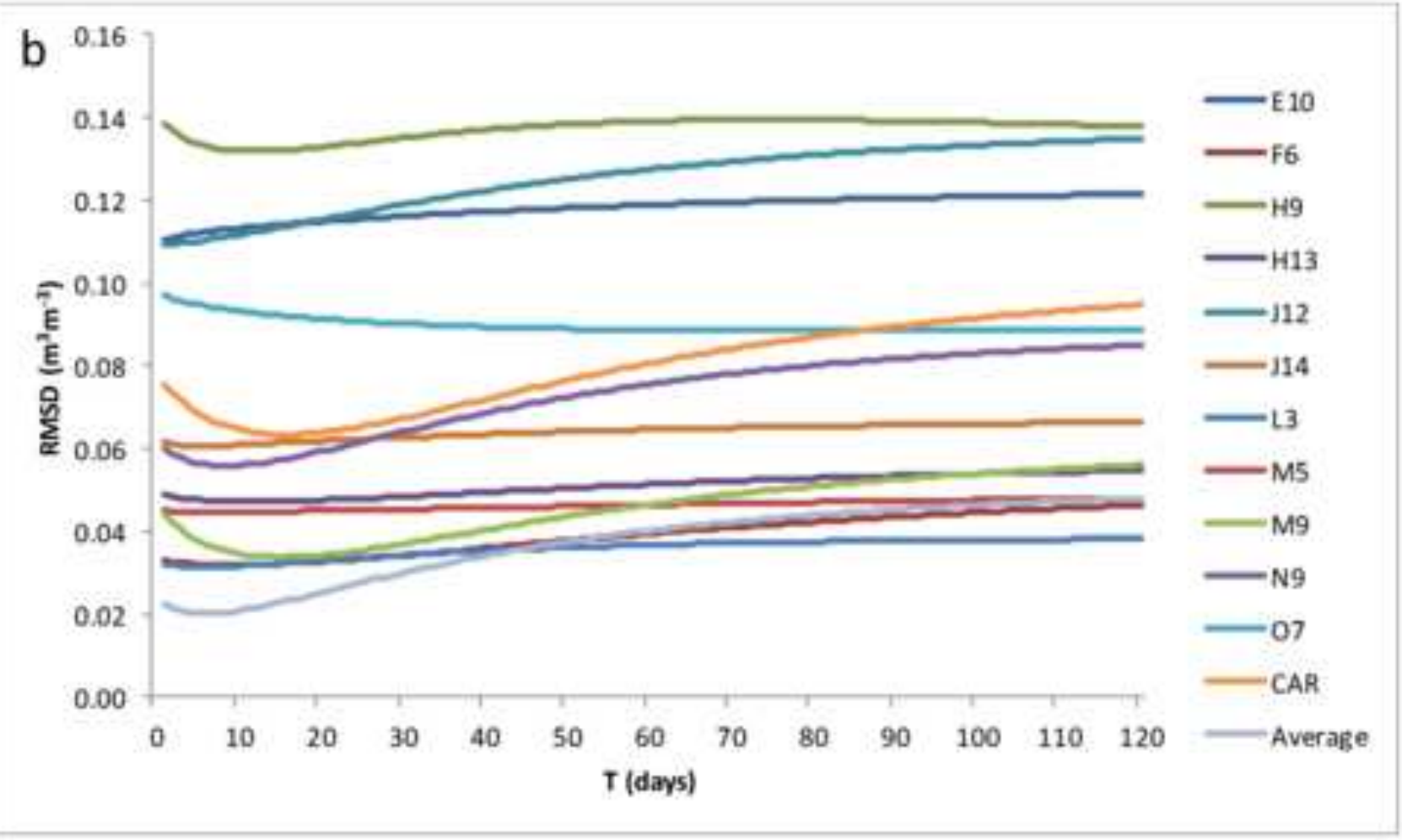




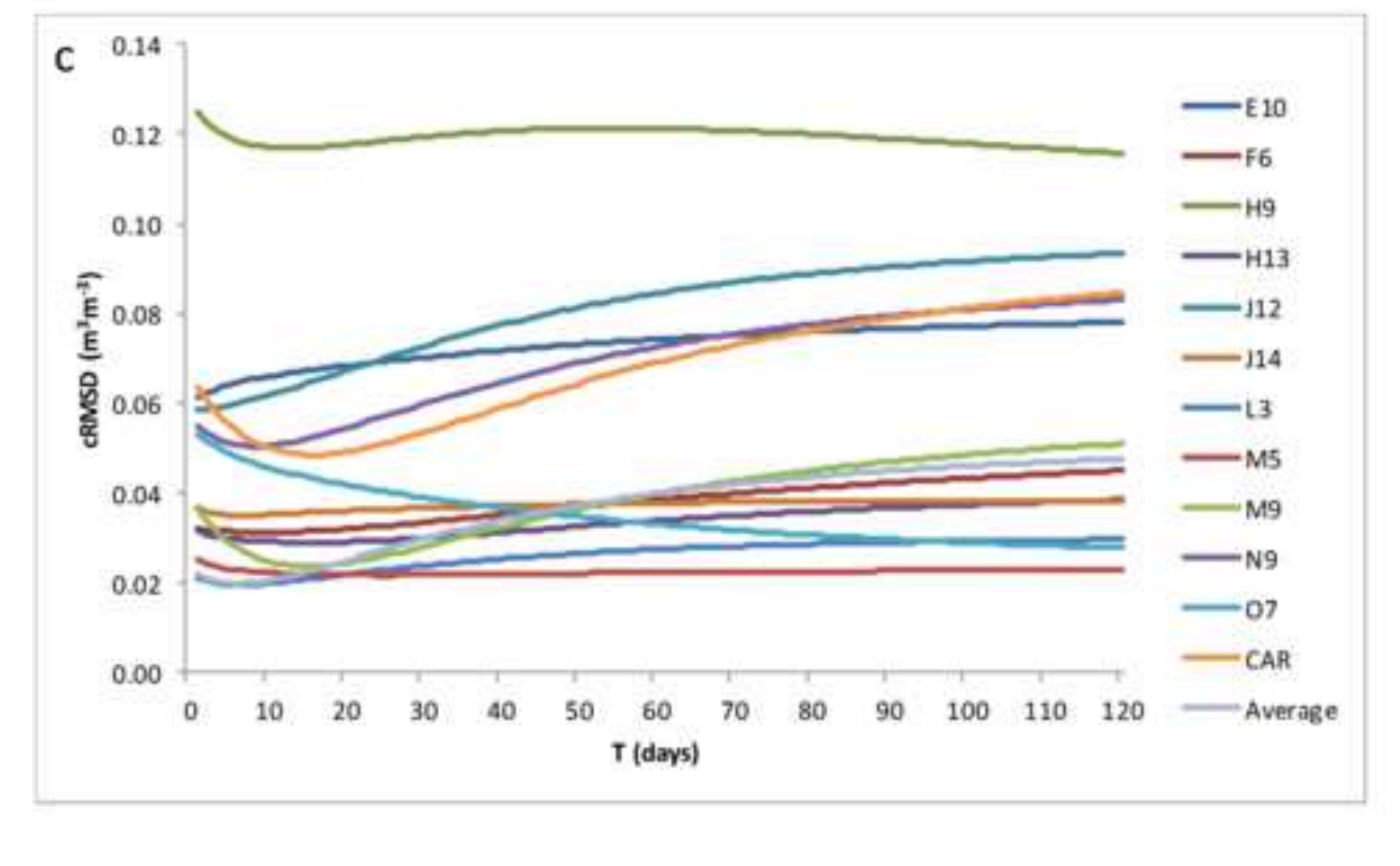

Figure 5c
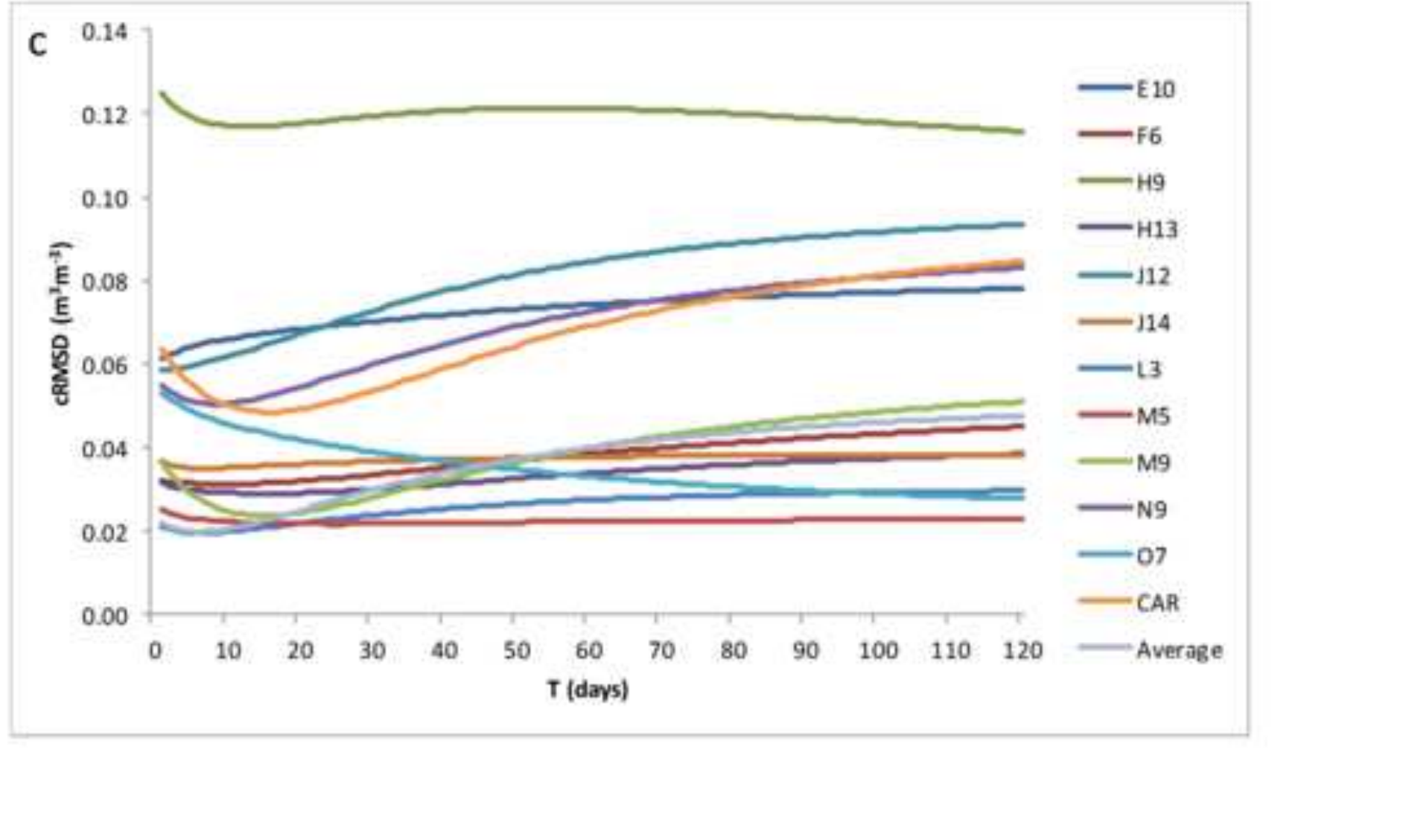

c

\section{Figure 50}
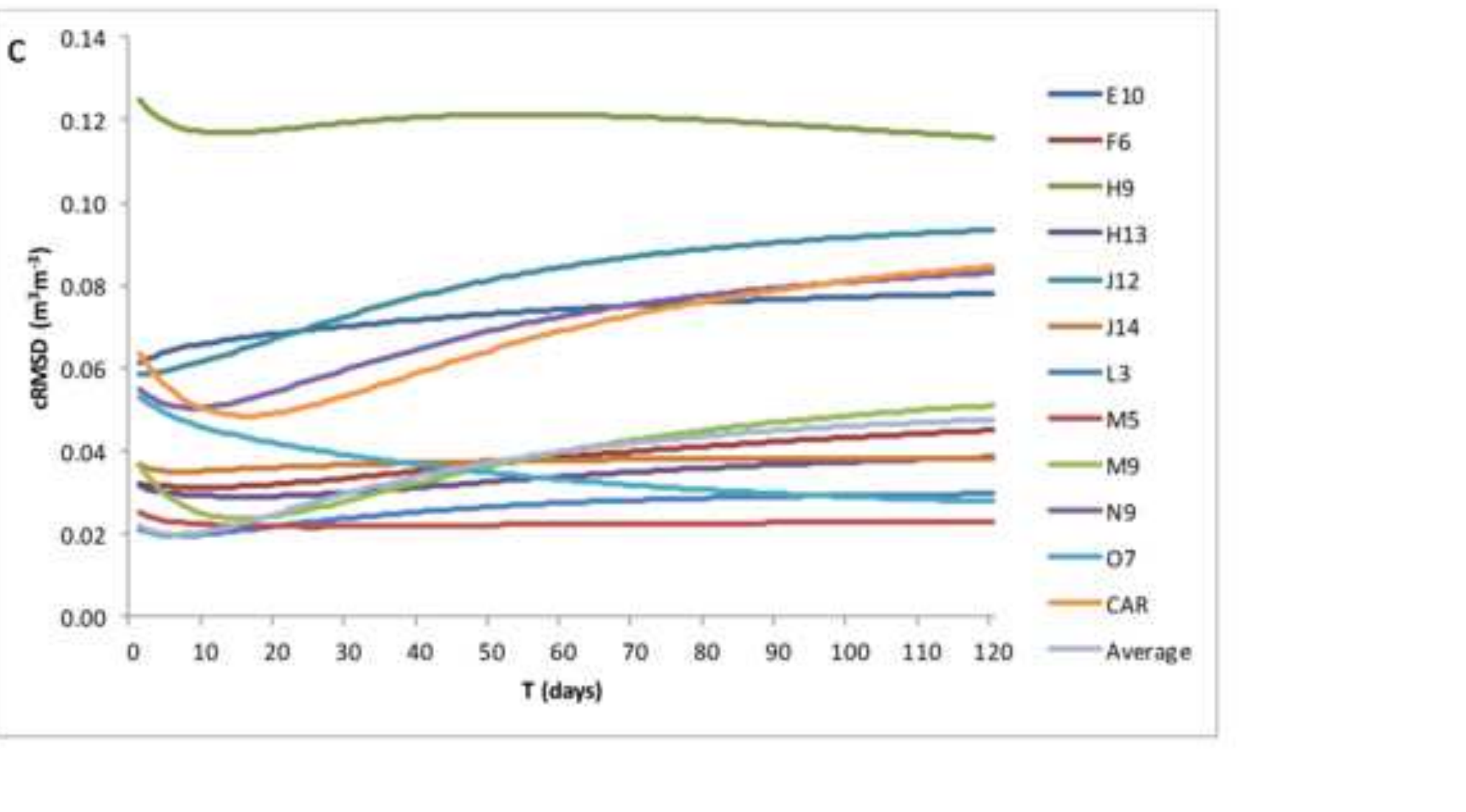


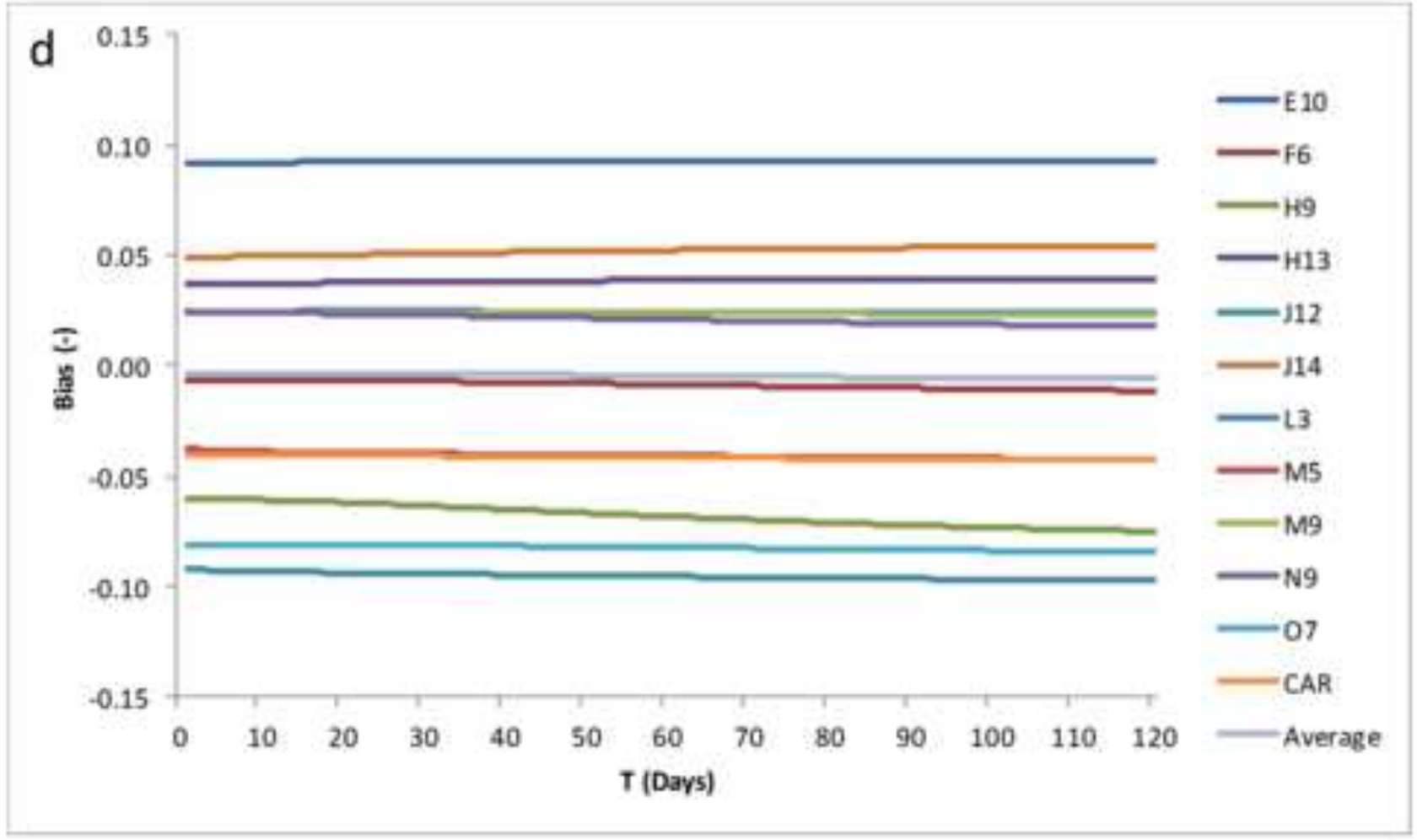




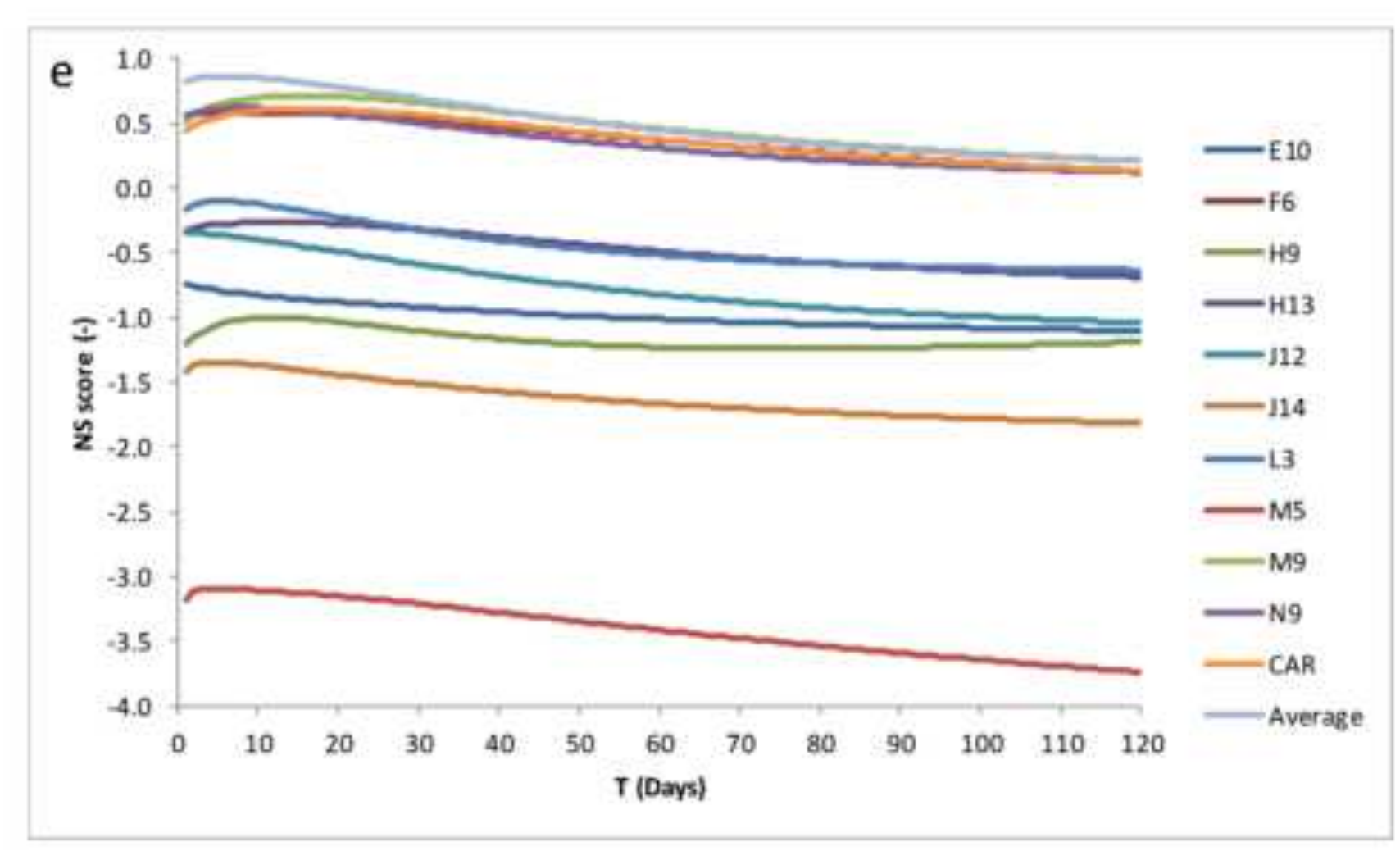

\author{
Figure 5
}
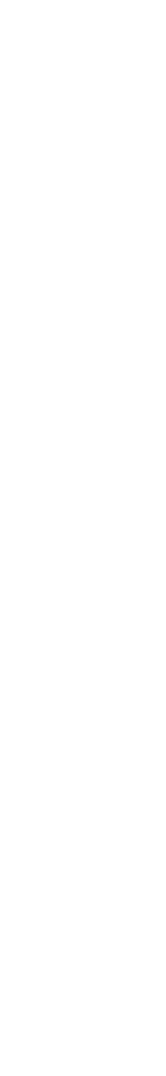


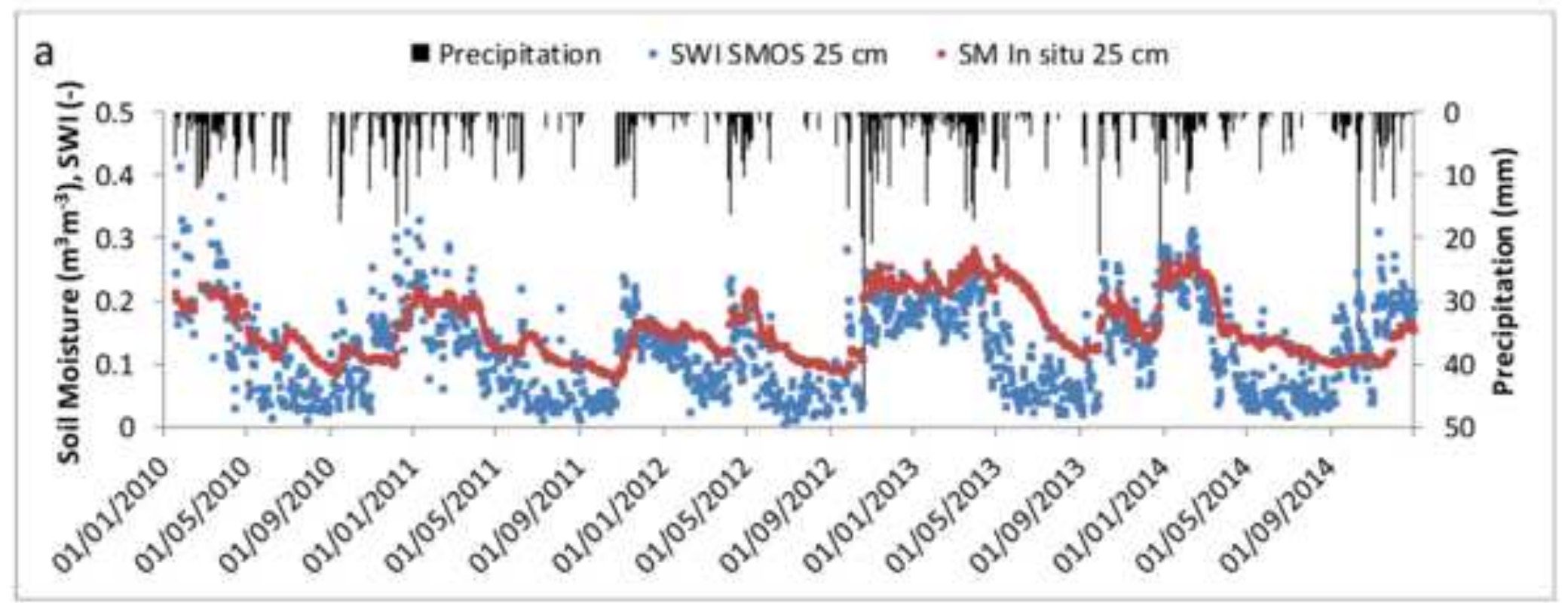




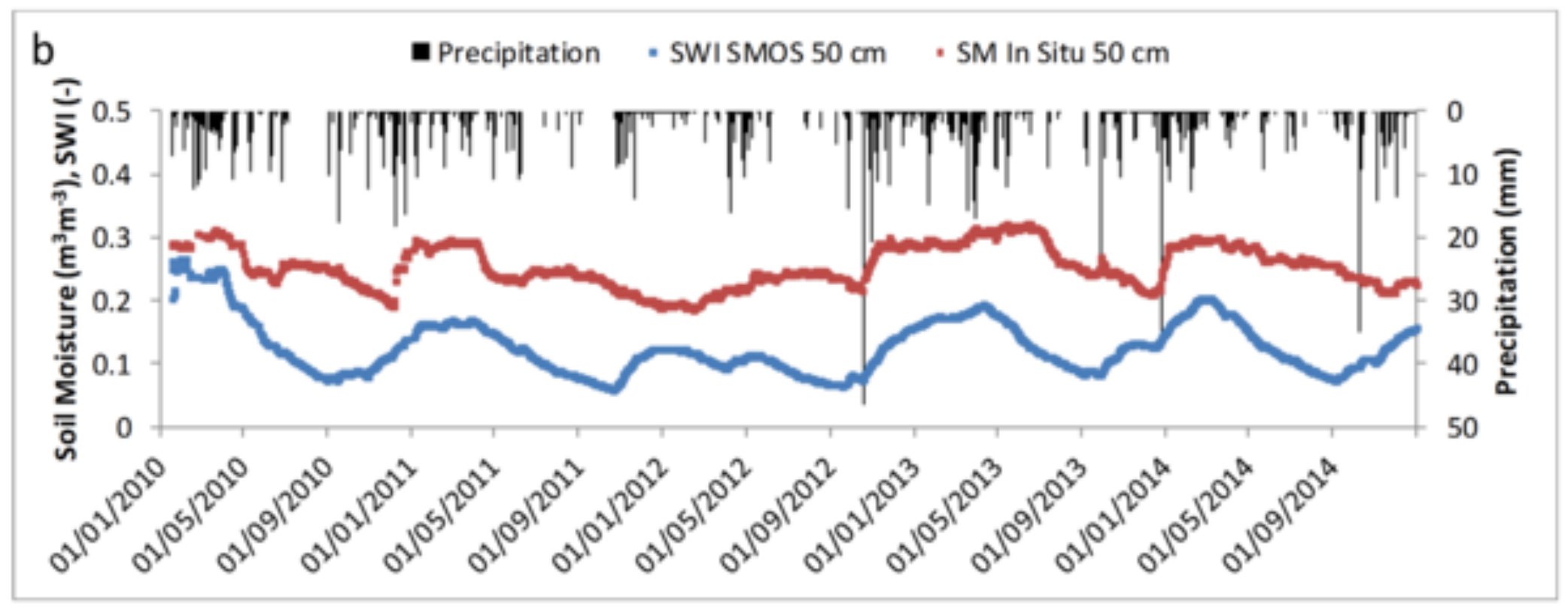




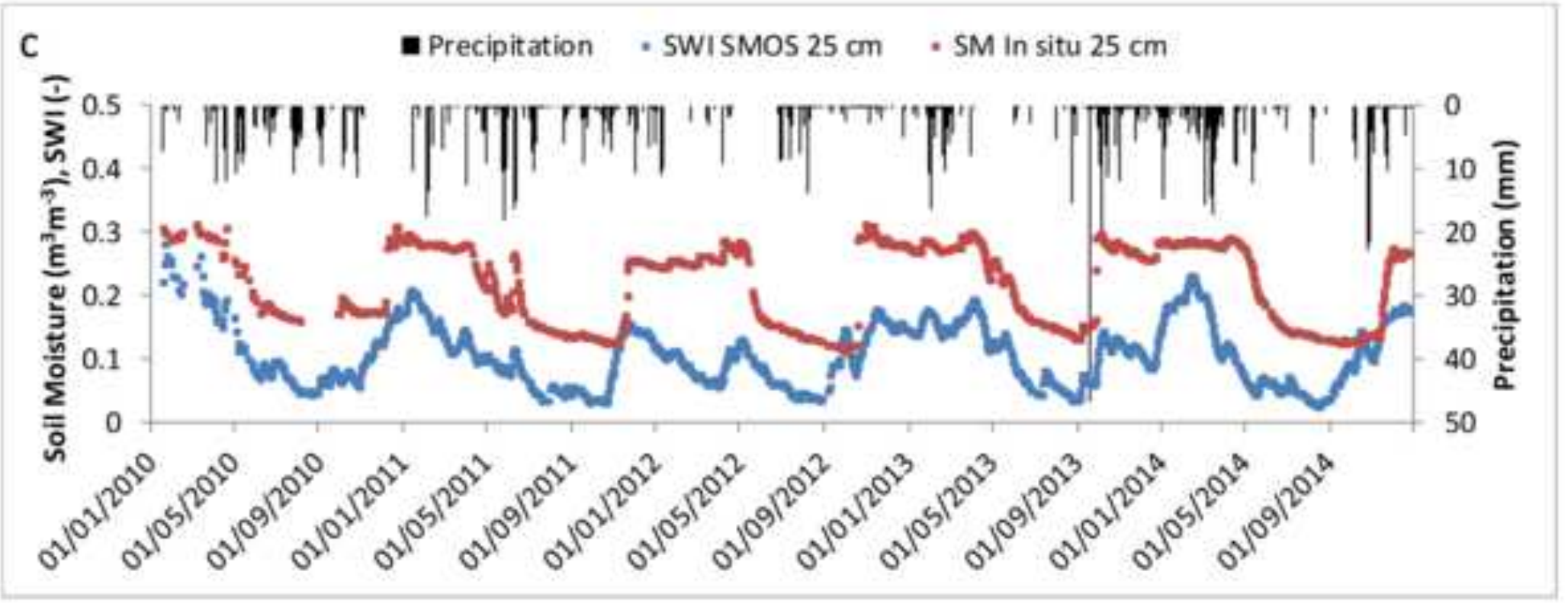




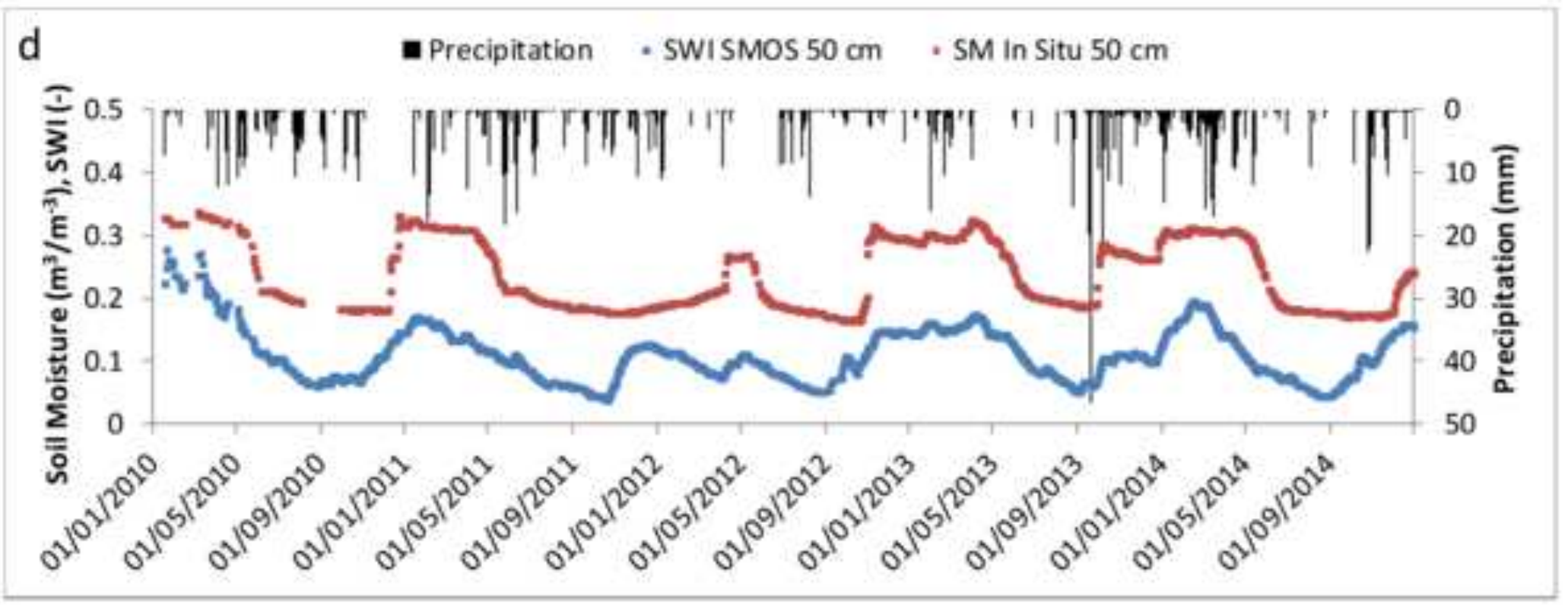




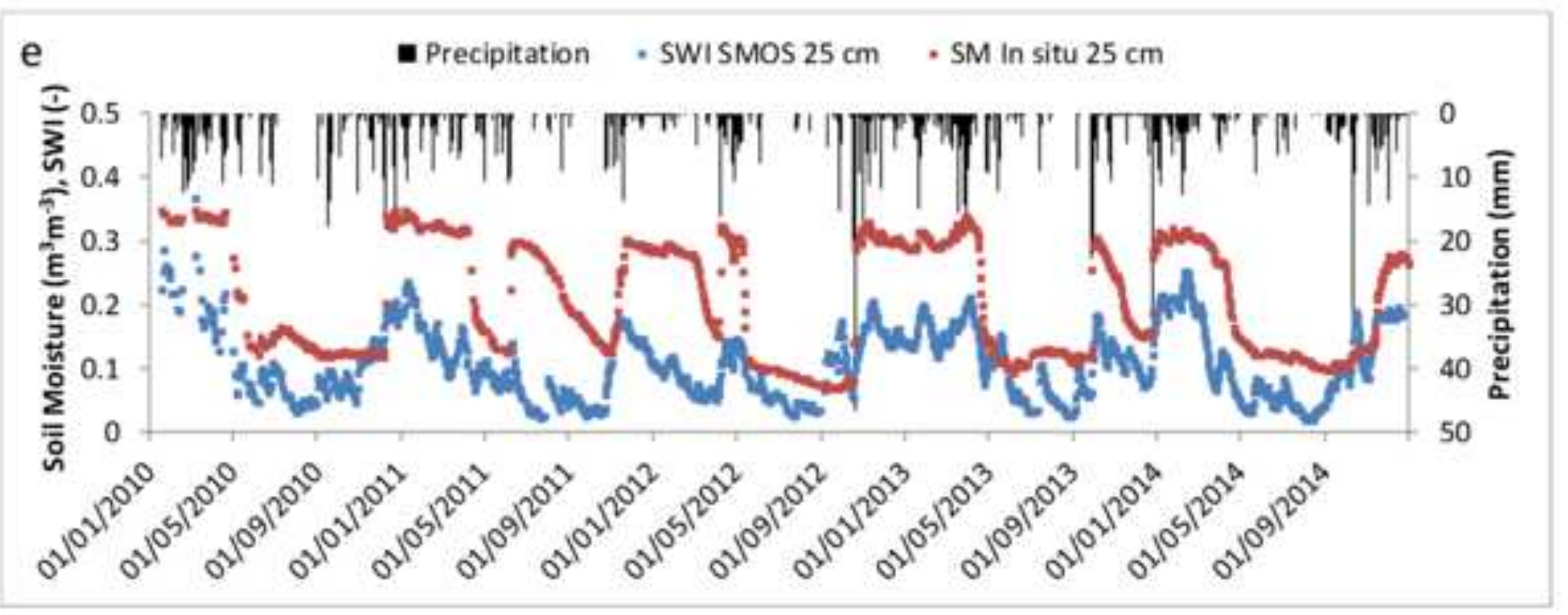




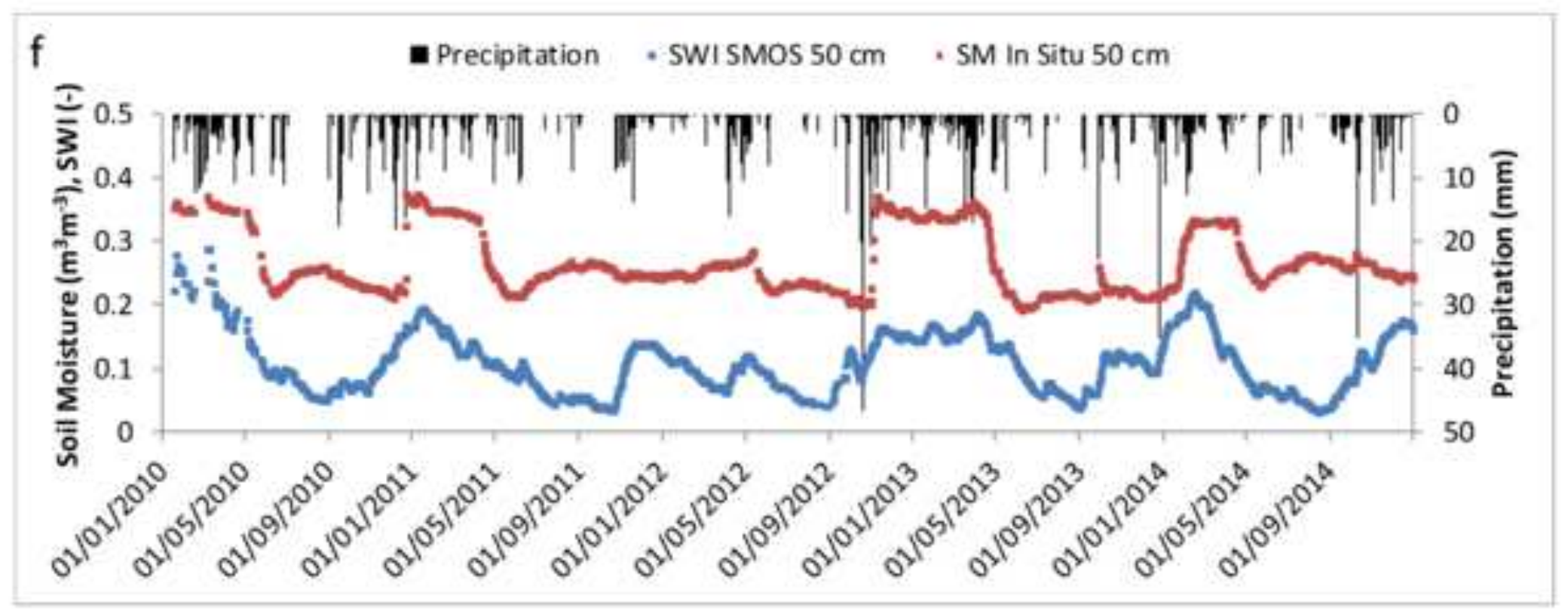




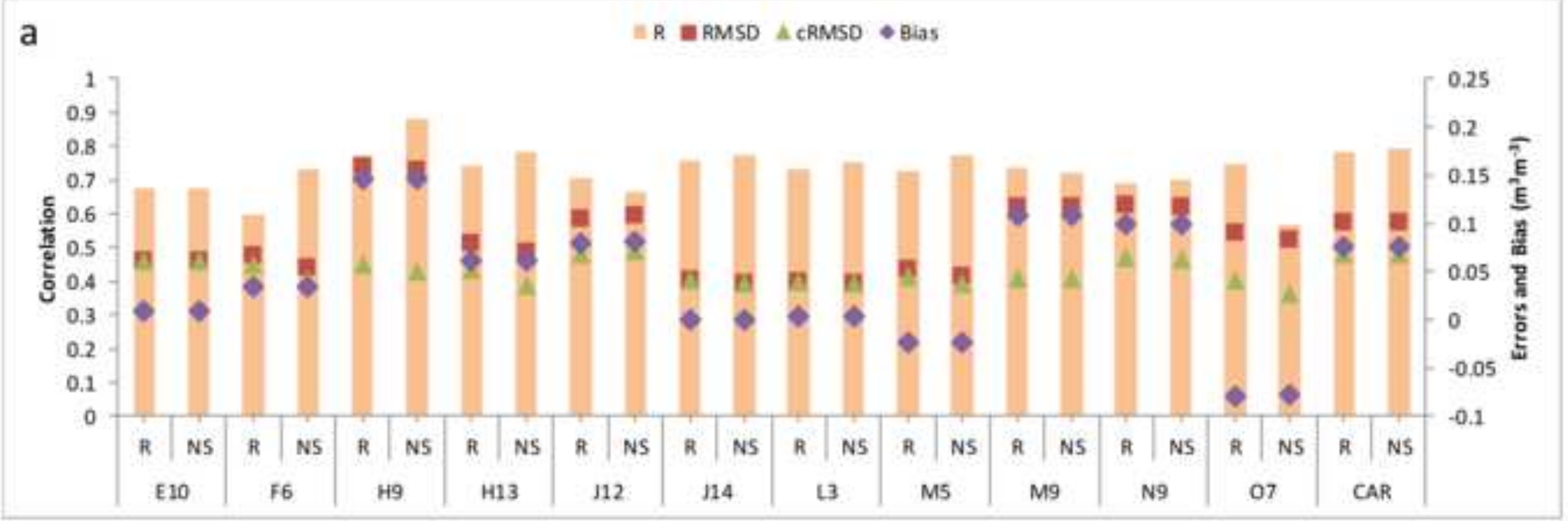




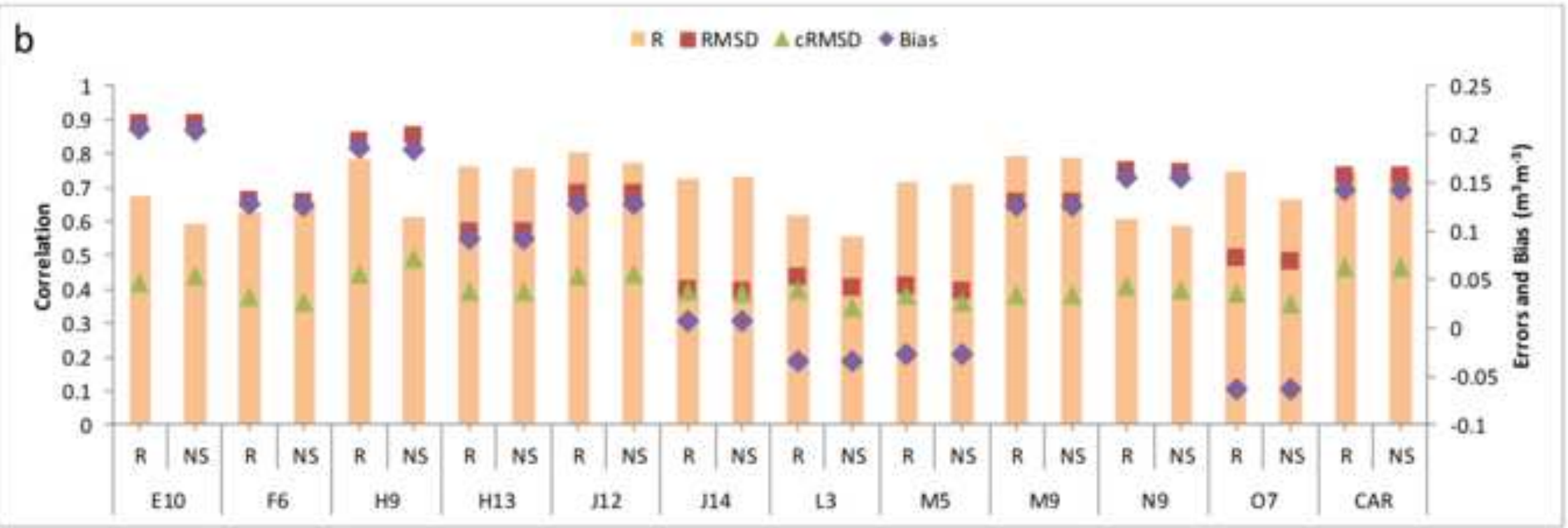




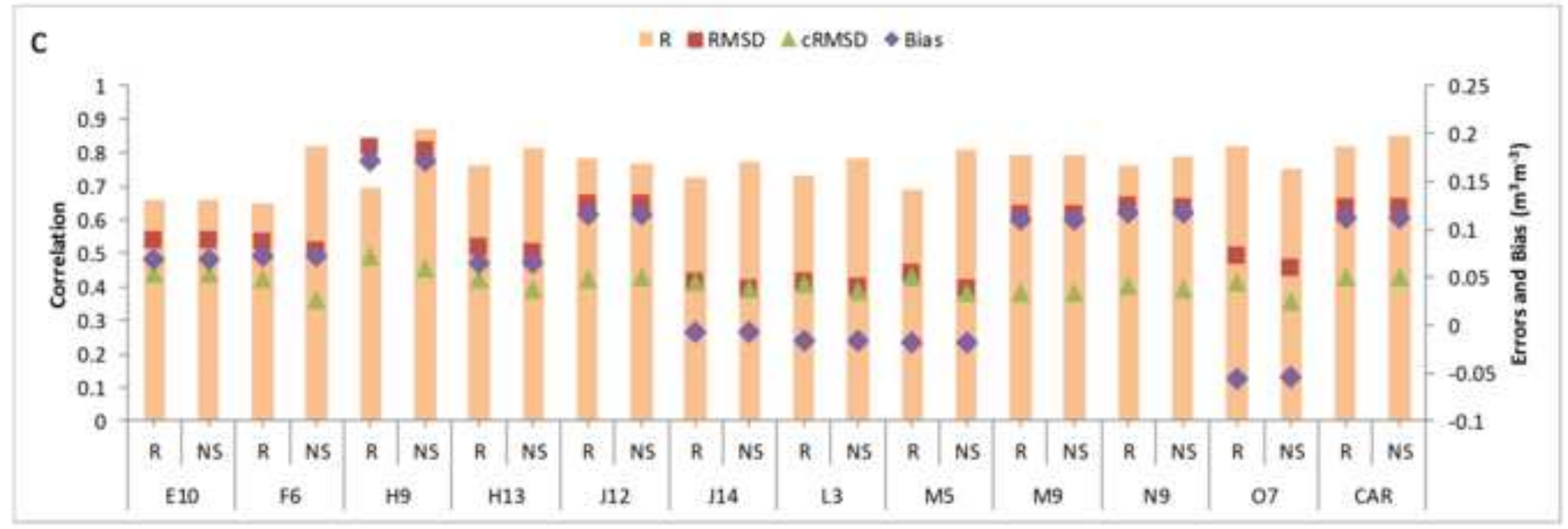


Figure 8
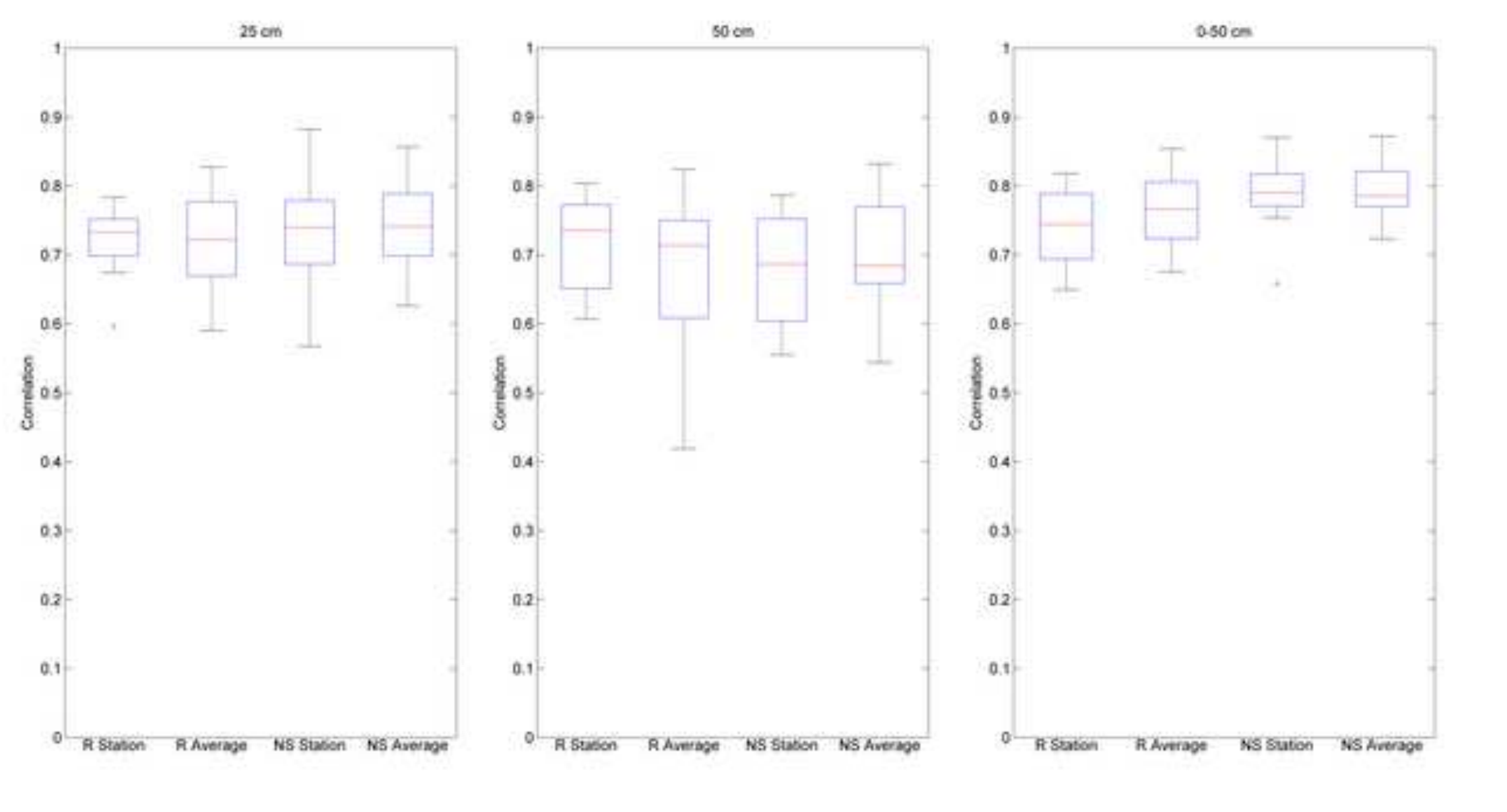

\section{Figure 8}
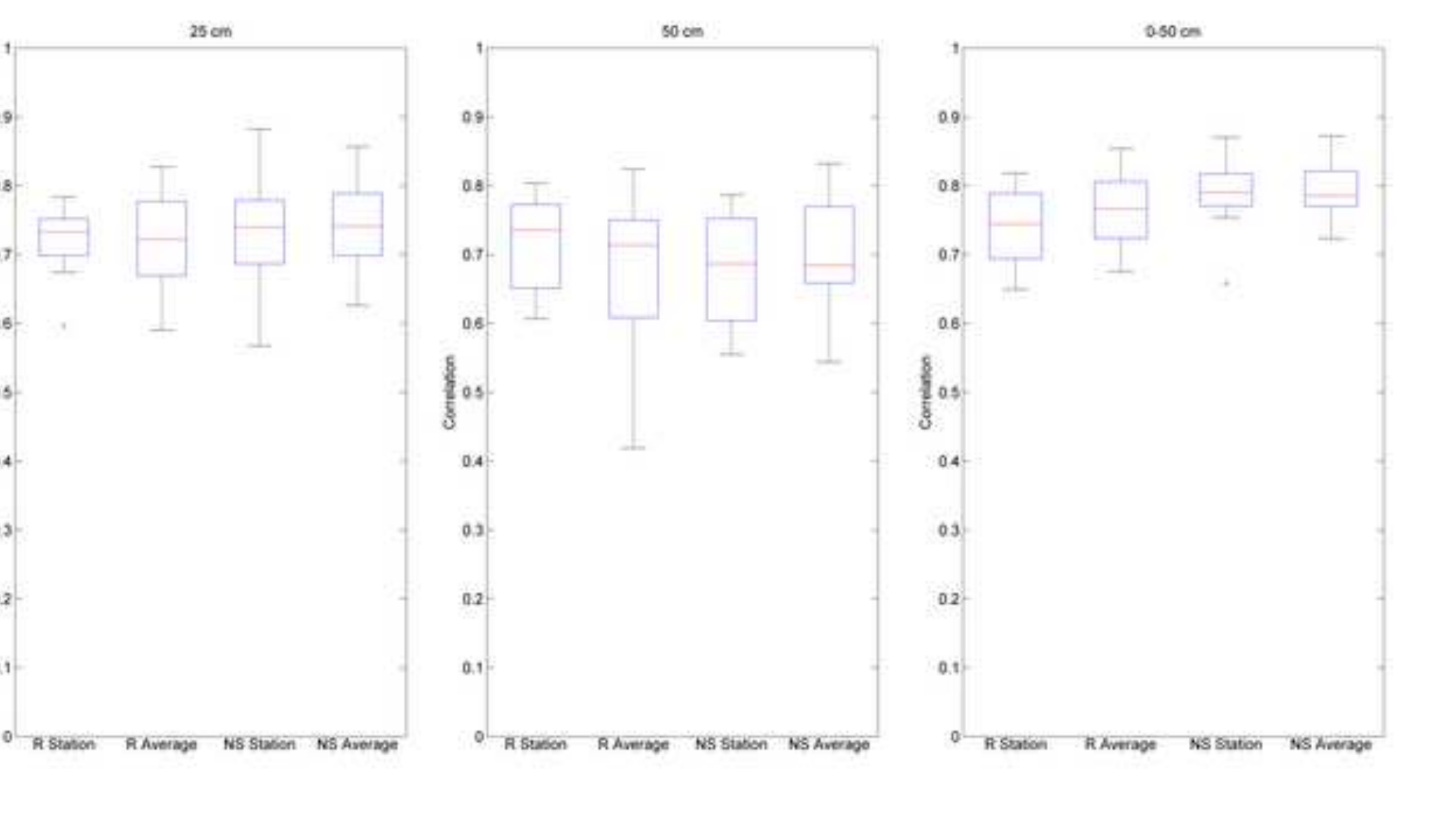

.

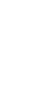




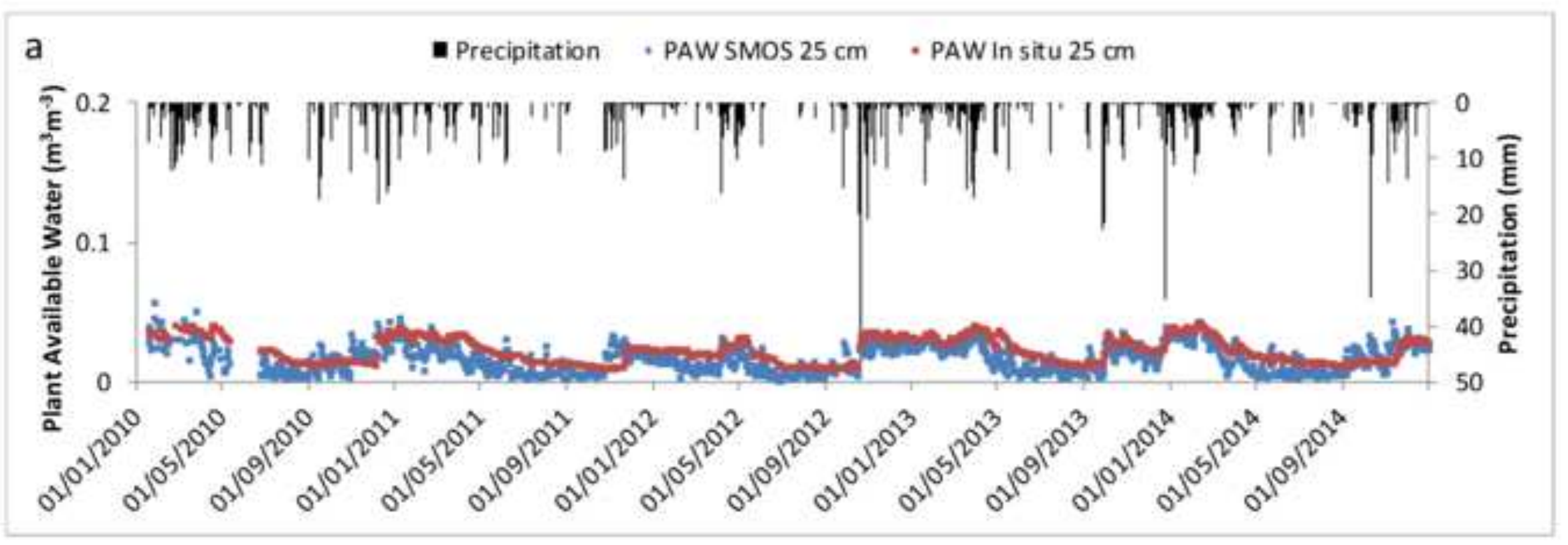




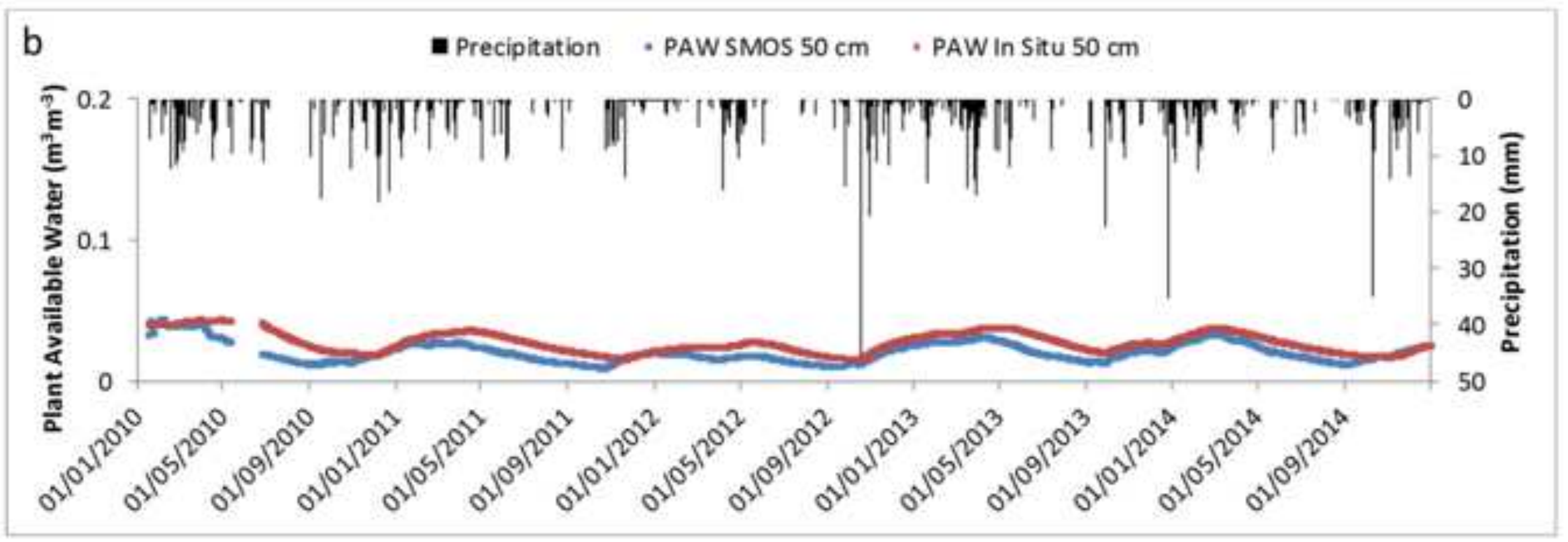




\section{Figure 9c
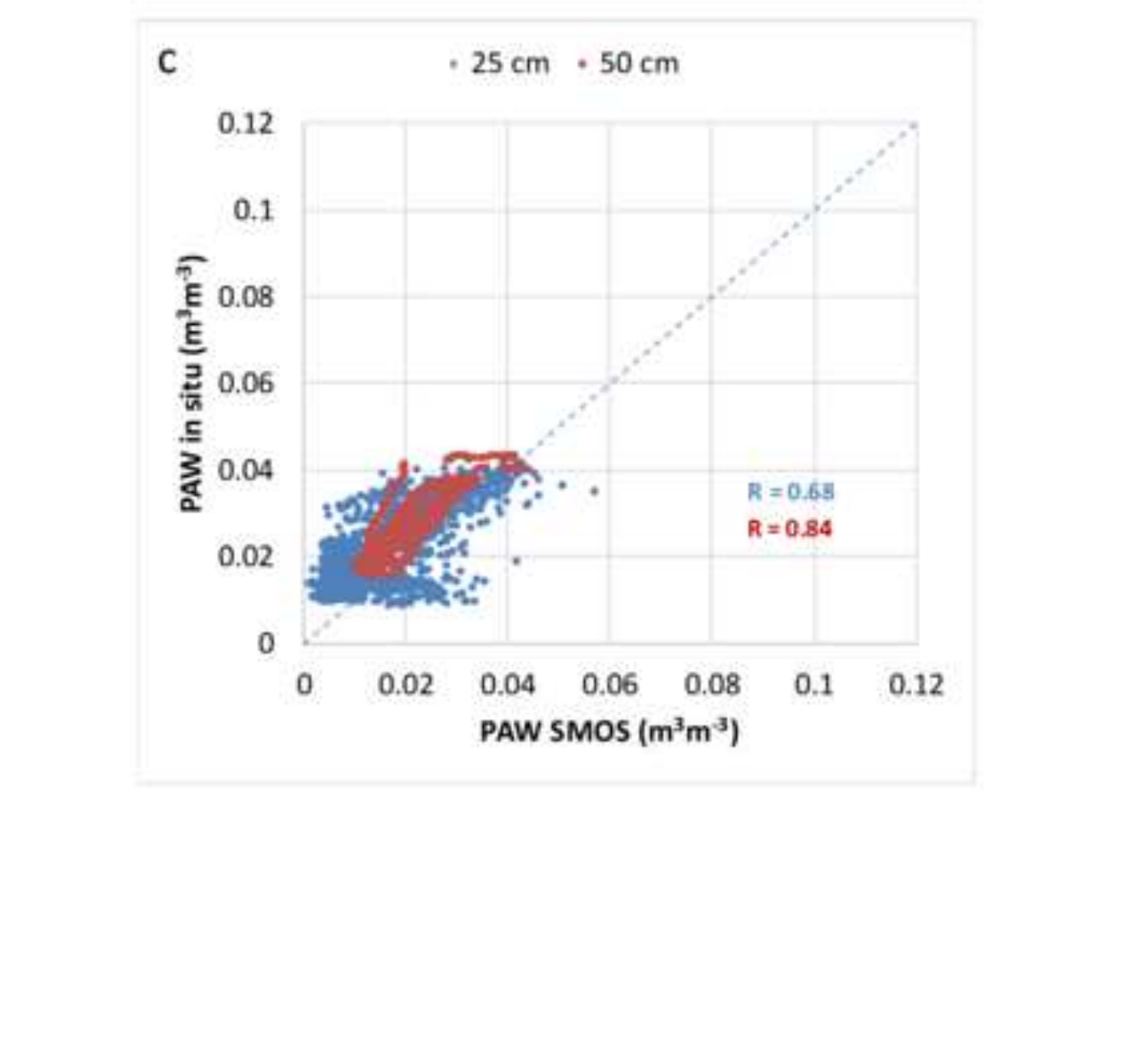

tats
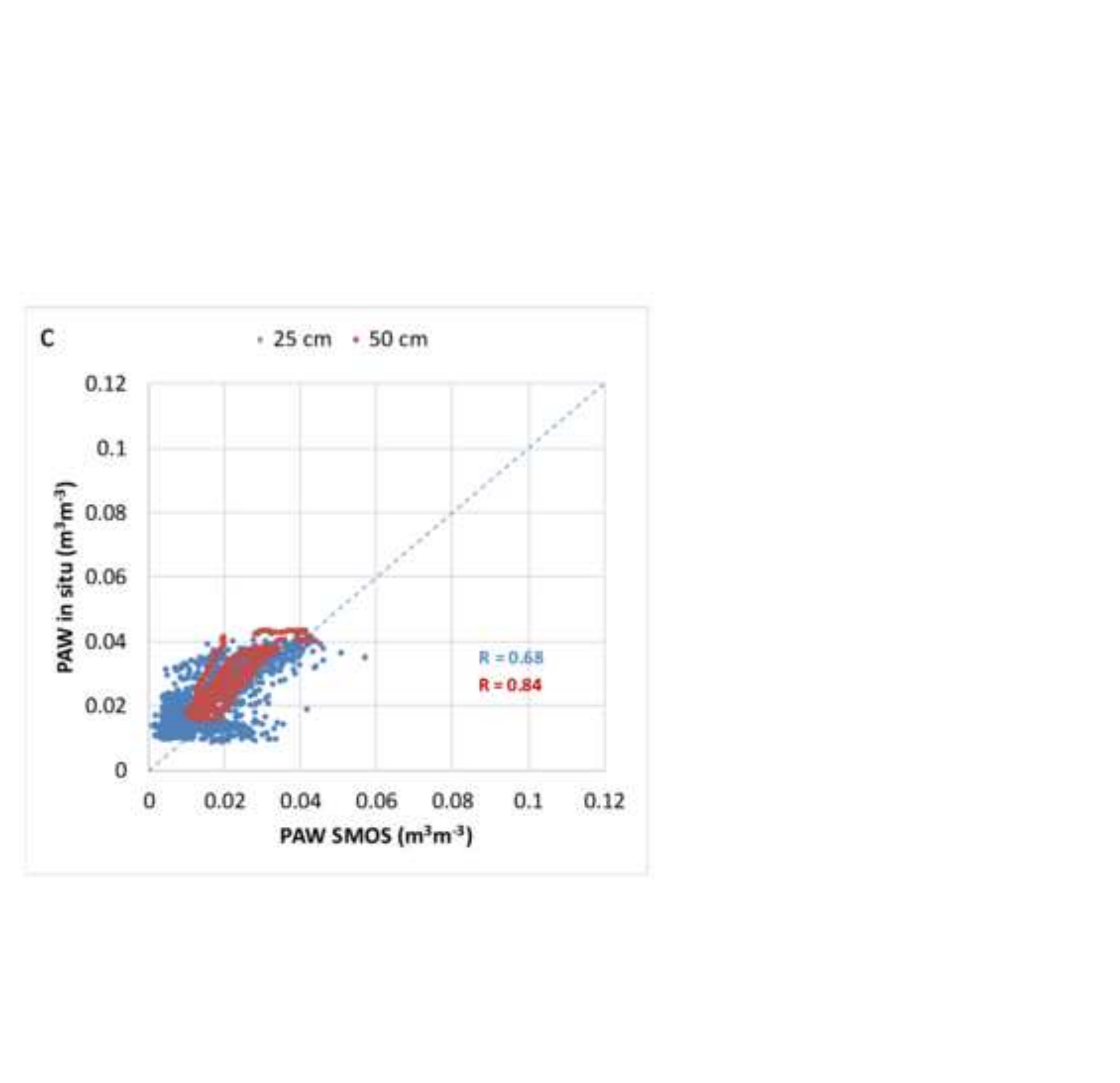


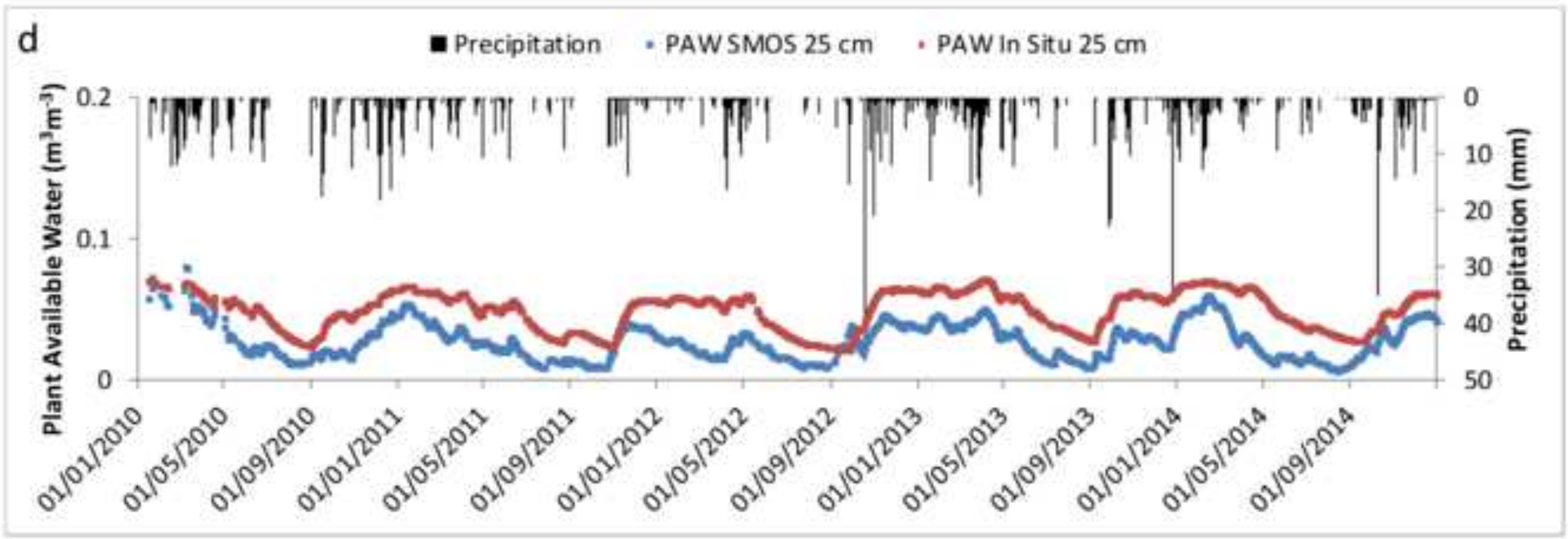




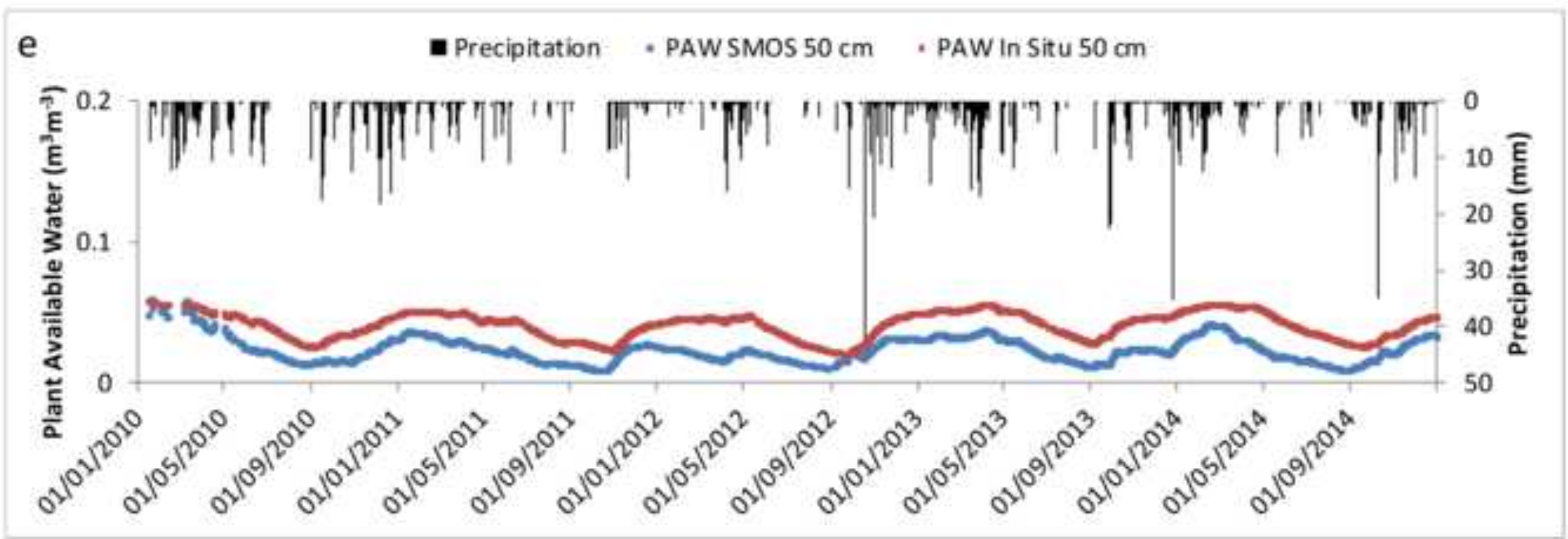



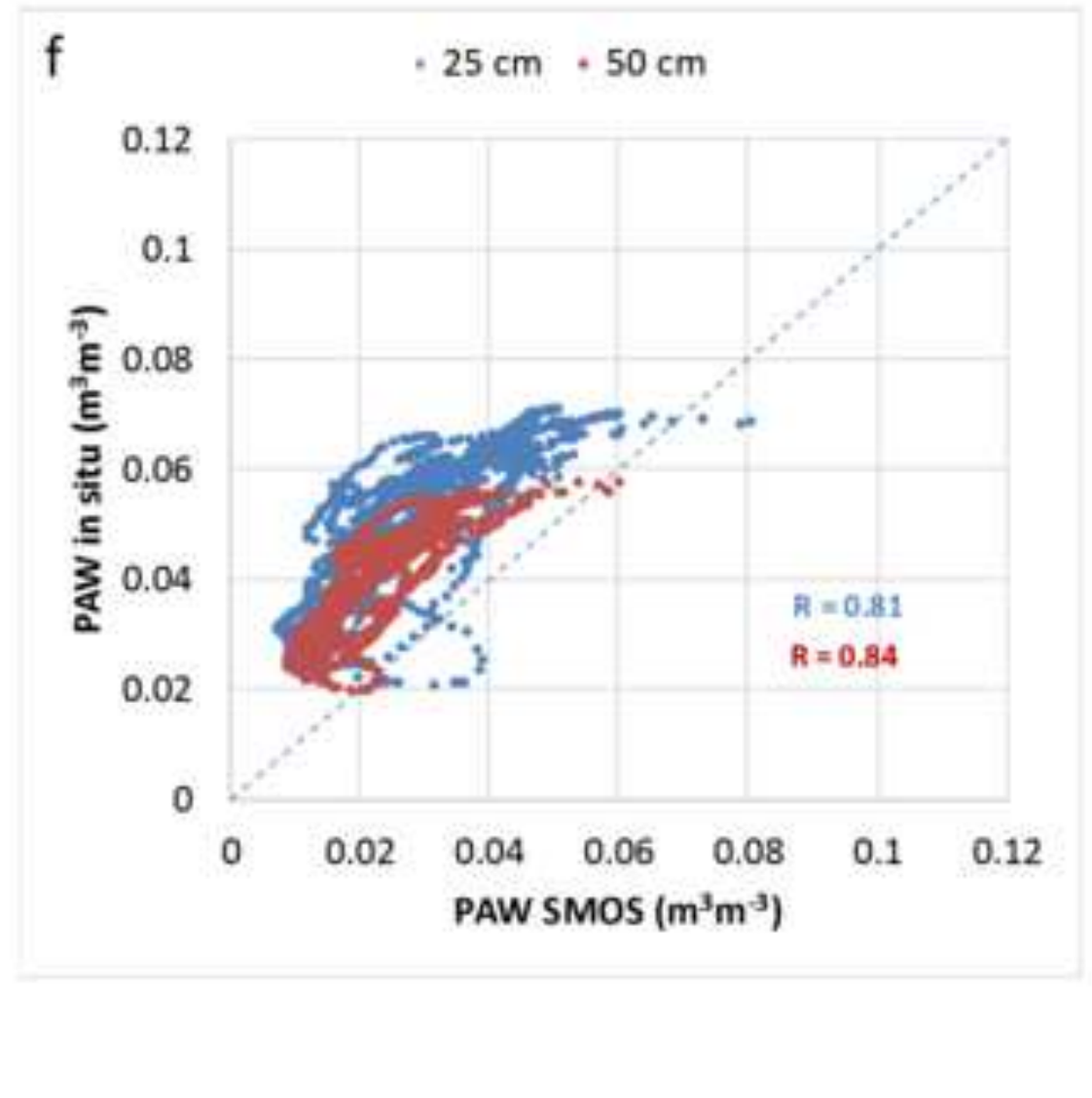


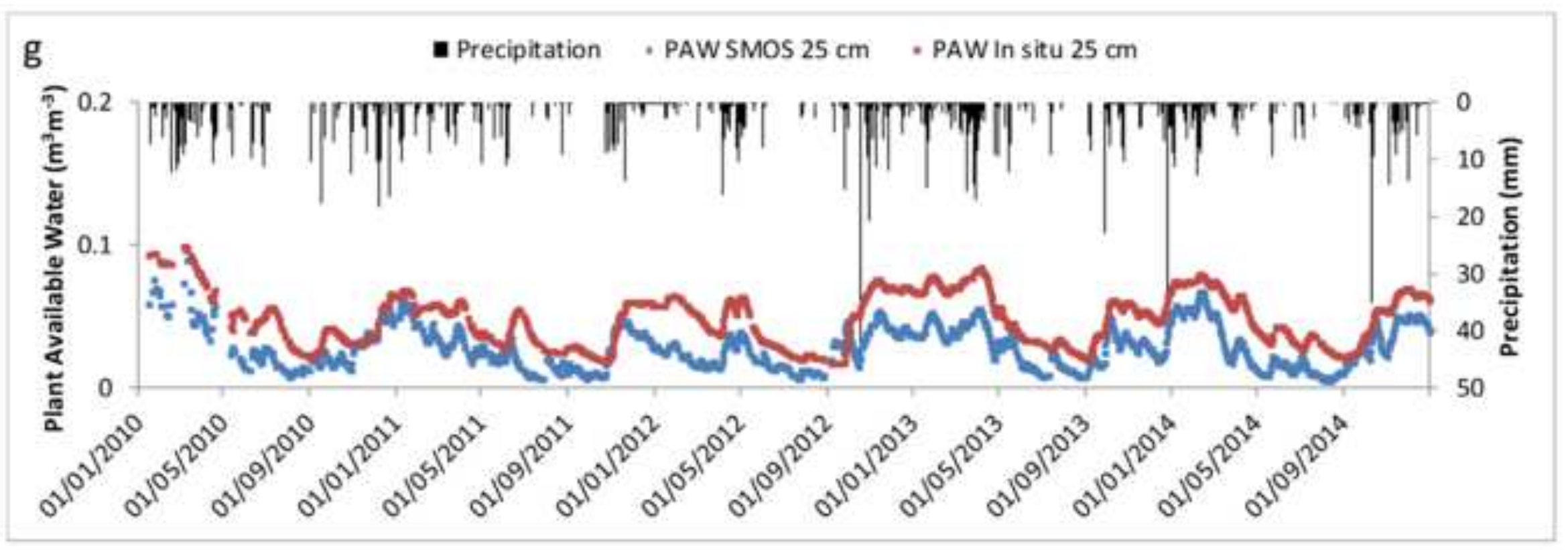




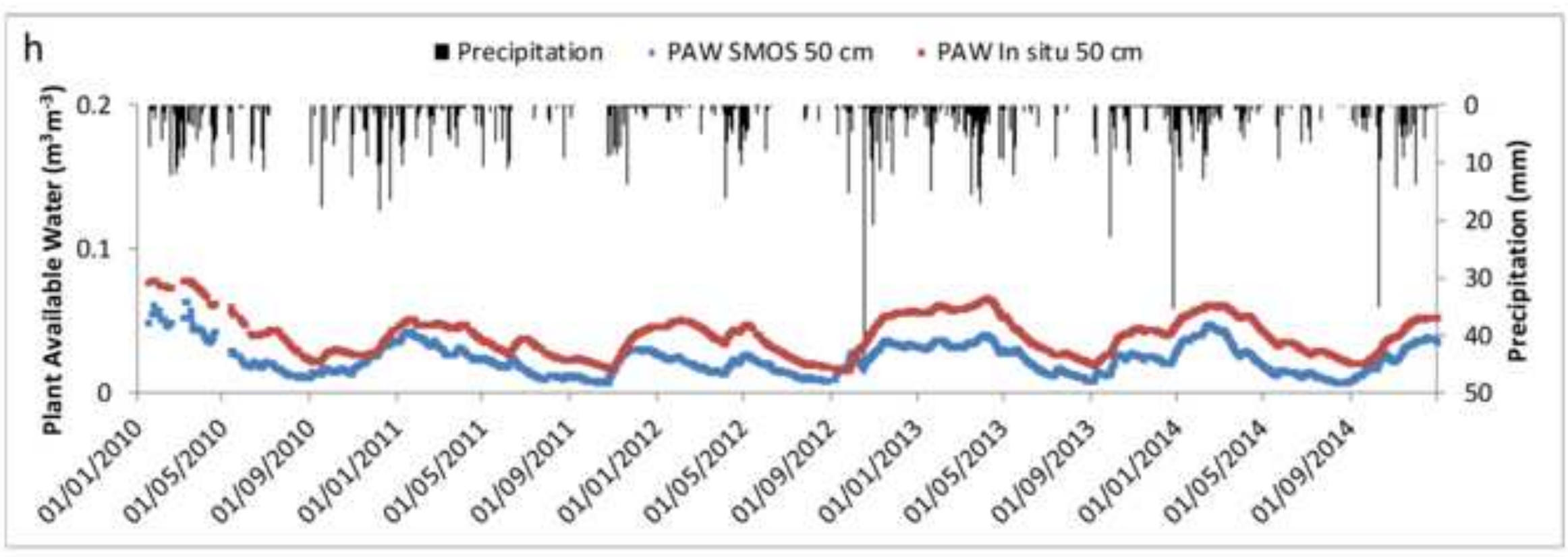




\section{Figure $9 i$}

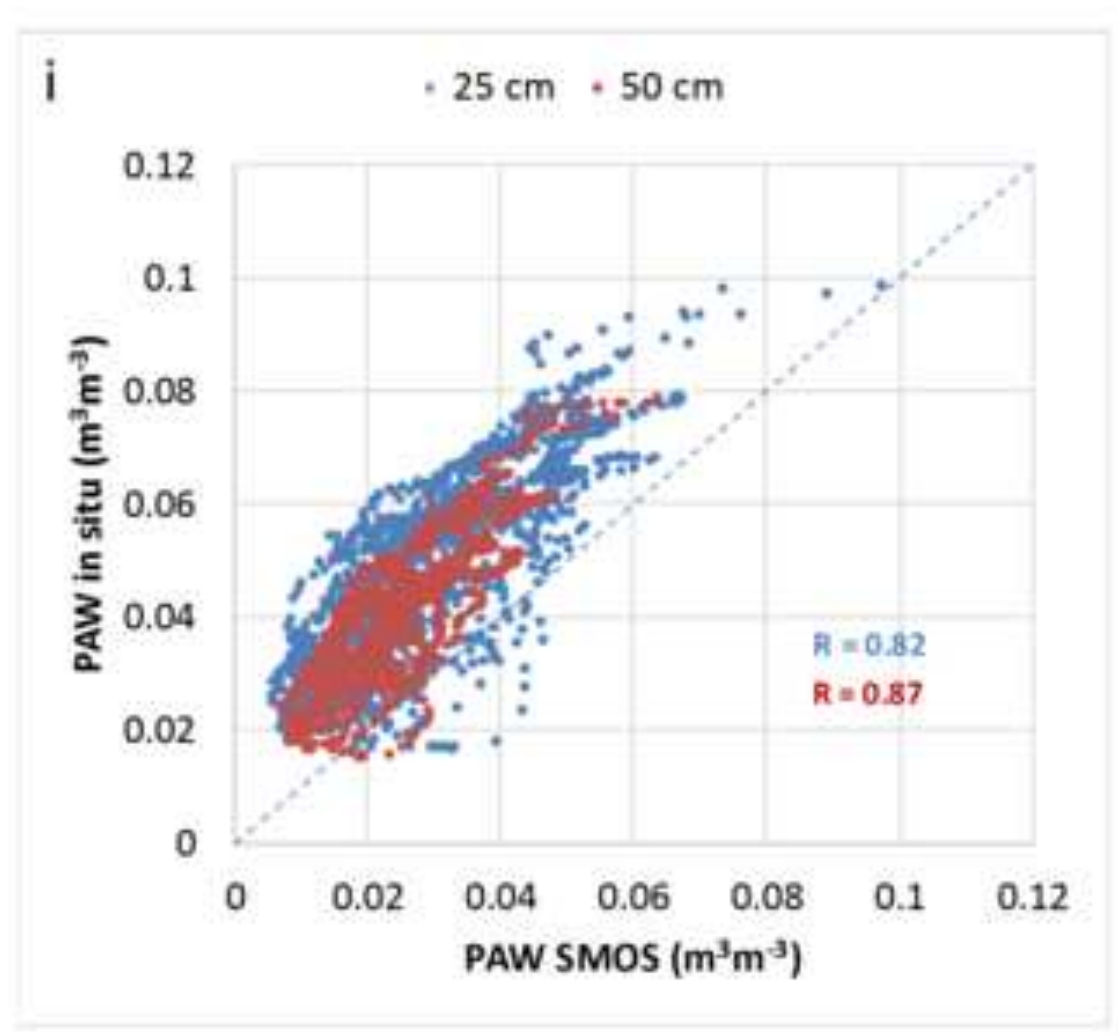




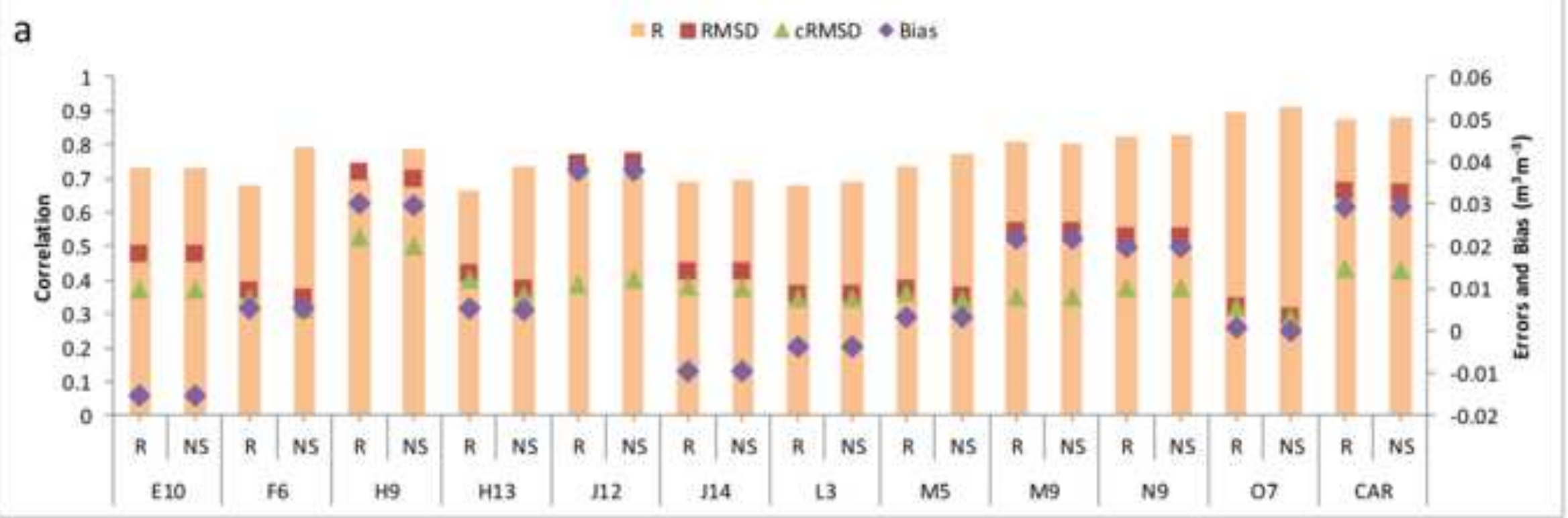




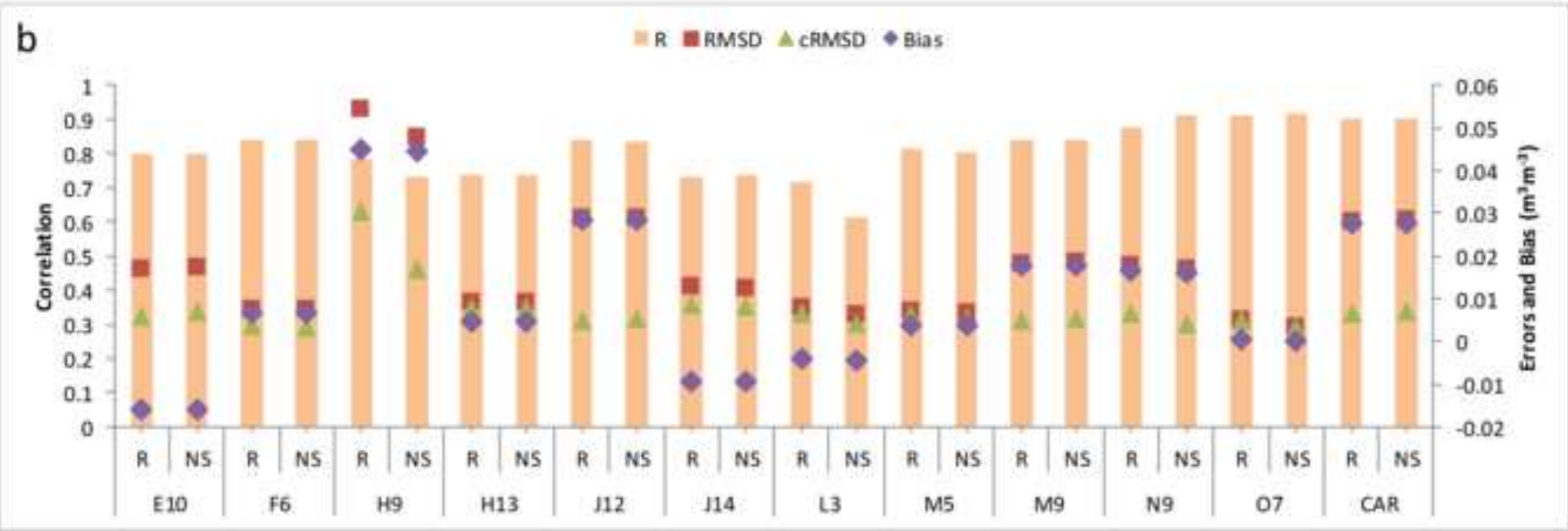




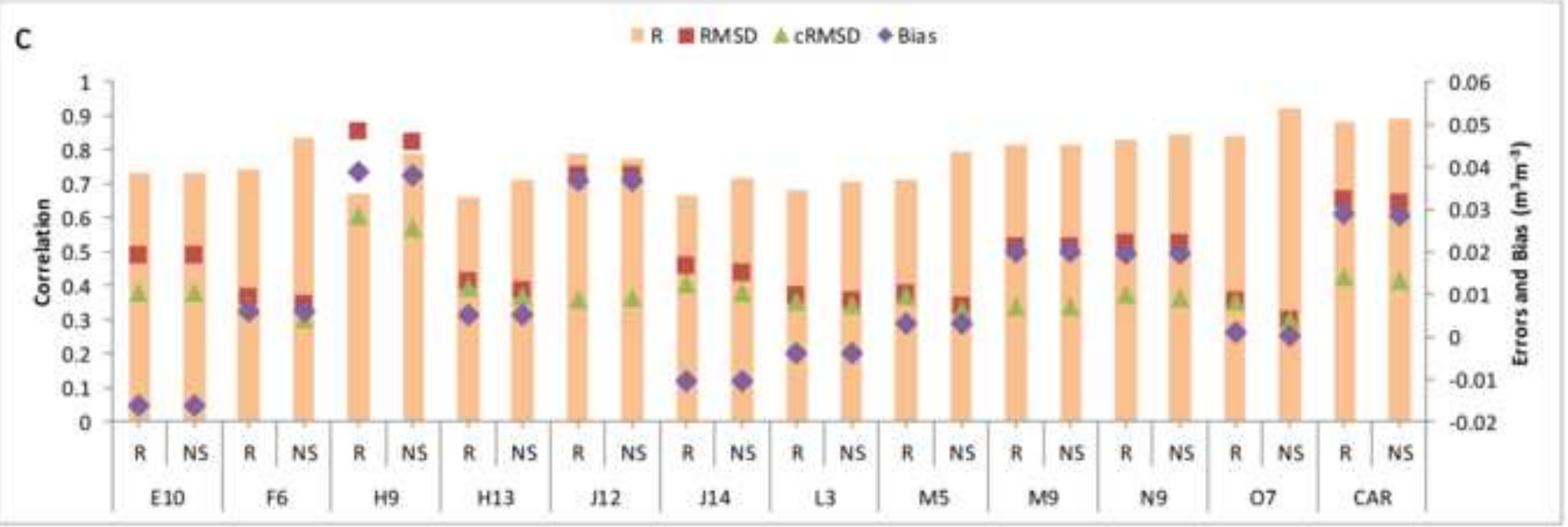




\begin{tabular}{|c|c|c|c|c|c|c|}
\hline Station & Land use & Depth $(\mathrm{cm})$ & Texture & $\Theta_{\mathrm{FC}}\left(m^{3} m^{-3}\right)$ & $\Theta_{W P}\left(m^{3} m^{-3}\right)$ & $\Theta_{\text {TWC }}\left(m^{3} m^{-3}\right)$ \\
\hline \multirow{3}{*}{ E10 } & \multirow{3}{*}{ Vineyard } & 5 & Sandy Loam & 0.088 & 0.028 & 0.410 \\
\hline & & 25 & Sandy Loam & 0.108 & 0.047 & 0.367 \\
\hline & & 50 & Sandy Clay Loam & 0.193 & 0.099 & 0.397 \\
\hline \multirow{3}{*}{ F6 } & \multirow{3}{*}{ Vineyard } & 5 & Sandy Loam & 0.229 & 0.111 & 0.324 \\
\hline & & 25 & Sandy Clay Loam & 0.207 & 0.113 & 0.294 \\
\hline & & 50 & Sandy Loam & 0.108 & 0.063 & 0.347 \\
\hline \multirow{3}{*}{ H9 } & \multirow{3}{*}{$\begin{array}{l}\text { Forest- } \\
\text { Pasture }\end{array}$} & 5 & Silty Clay Loam & 0.305 & 0.205 & 0.483 \\
\hline & & 25 & Loam & 0.232 & 0.171 & 0.394 \\
\hline & & 50 & Clay Loam & 0.290 & 0.177 & 0.489 \\
\hline \multirow{3}{*}{$\mathrm{H} 13$} & \multirow{3}{*}{$\begin{array}{l}\text { Forest- } \\
\text { Pasture }\end{array}$} & 5 & Sandy Loam & 0.158 & 0.075 & 0.424 \\
\hline & & 25 & Sandy Loam & 0.138 & 0.071 & 0.446 \\
\hline & & 50 & Sandy Loam & 0.113 & 0.076 & 0.447 \\
\hline \multirow{3}{*}{ J12 } & \multirow{3}{*}{ Rainfed } & 5 & Sandy Clay Loam & 0.236 & 0.096 & 0.483 \\
\hline & & 25 & Sandy Clay Loam & 0.228 & 0.113 & 0.456 \\
\hline & & 50 & Sandy Clay Loam & 0.265 & 0.168 & 0.415 \\
\hline \multirow{3}{*}{ J14 } & \multirow{3}{*}{ Rainfed } & 5 & Sandy Loam & 0.141 & 0.041 & 0.541 \\
\hline & & 25 & Sandy Loam & 0.153 & 0.052 & 0.377 \\
\hline & & 50 & Sandy Loam & 0.156 & 0.052 & 0.370 \\
\hline \multirow{3}{*}{ L3 } & \multirow{3}{*}{ Vineyard } & 5 & Loamy Sand & 0.125 & 0.04 & 0.427 \\
\hline & & 25 & Loamy Sand & 0.146 & 0.056 & 0.348 \\
\hline & & 50 & Loamy Sand & 0.130 & 0.043 & 0.370 \\
\hline \multirow{3}{*}{ M5 } & \multirow{3}{*}{ Rainfed } & 5 & Loamy Sand & 0.100 & 0.057 & 0.357 \\
\hline & & 25 & Loamy Sand & 0.125 & 0.042 & 0.406 \\
\hline & & 50 & Loamy Sand & 0.071 & 0.043 & 0.507 \\
\hline \multirow{3}{*}{ M9 } & \multirow{3}{*}{ Rainfed } & 5 & Sandy Clay Loam & 0.226 & 0.137 & 0.519 \\
\hline & & 25 & Sandy Clay Loam & 0.238 & 0.124 & 0.527 \\
\hline & & 50 & Loam & 0.214 & 0.146 & 0.508 \\
\hline \multirow{3}{*}{ N9 } & \multirow{3}{*}{ Rainfed } & 5 & Sandy Clay Loam & 0.220 & 0.082 & 0.558 \\
\hline & & 25 & Sandy Loam & 0.274 & 0.140 & 0.536 \\
\hline & & 50 & Loam & 0.334 & 0.218 & 0.544 \\
\hline \multirow{3}{*}{07} & \multirow{3}{*}{ Rainfed } & 5 & Loamy Sand & 0.076 & 0.021 & 0.512 \\
\hline & & 25 & Sandy Loam & 0.093 & 0.035 & 0.447 \\
\hline & & 50 & Loamy Sand & 0.083 & 0.035 & 0.468 \\
\hline \multirow{3}{*}{ CAR } & \multirow{3}{*}{ Rainfed } & 5 & Loam & 0.256 & 0.137 & 0.505 \\
\hline & & 25 & Sandy Clay Loam & 0.239 & 0.127 & 0.515 \\
\hline & & 50 & Sandy Clay Loam & 0.218 & 0.109 & 0.500 \\
\hline
\end{tabular}

Table 1. Land use, texture, field capacity $\left(\Theta_{\mathrm{FC}}\right)$, wilting point $\left(\Theta_{\mathrm{WP}}\right)$ and total water capacity $\left(\Theta_{\mathrm{TWC}}\right)$ at the different depths of each REMEDHUS station used in the study. 
Table 2

\begin{tabular}{|c|c|c|c|c|c|c|c|c|c|c|c|c|c|}
\cline { 2 - 14 } \multicolumn{1}{c|}{} & E10 & F6 & H9 & H13 & J12 & J14 & L3 & M5 & M9 & N9 & O7 & CAR & Area-Average \\
\hline R & 1 & 1 & 2 & 1 & 2 & 3 & 4 & 2 & 17 & 8 & 12 & 14 & 4 \\
\hline RMSD & 1 & 10 & 12 & 13 & 1 & 5 & 5 & 119 & 120 & 9 & 82 & 16 & 9 \\
\hline CRMSD & 1 & 10 & 120 & 16 & 2 & 6 & 6 & 25 & 15 & 8 & 120 & 16 & 6 \\
\hline Bias & 1 & 15 & 1 & 1 & 1 & 1 & 120 & 1 & 120 & 120 & 18 & 1 & 1 \\
\hline NS & 1 & 10 & 12 & 13 & 1 & 5 & 5 & 5 & 15 & 9 & 82 & 16 & 6 \\
\hline
\end{tabular}

Table 2. $\mathrm{T}_{\text {opt }}$ obtained by the different metrics at $25 \mathrm{~cm}$ depth. 
Table 3

\begin{tabular}{|c|c|c|c|c|c|c|c|c|c|c|c|c|c|}
\cline { 2 - 14 } \multicolumn{1}{c|}{} & E10 & F6 & H9 & H13 & J12 & J14 & L3 & M5 & M9 & N9 & O7 & CAR & Area-Average \\
\hline R & 27 & 71 & 11 & 12 & 20 & 10 & 19 & 19 & 43 & 25 & 20 & 120 & 21 \\
\hline RMSD & 10 & 120 & 120 & 14 & 15 & 13 & 120 & 46 & 40 & 120 & 71 & 106 & 45 \\
\hline CRMSD & 19 & 120 & 120 & 17 & 16 & 24 & 120 & 120 & 39 & 51 & 120 & 101 & 38 \\
\hline Bias & 1 & 120 & 1 & 1 & 1 & 1 & 20 & 1 & 120 & 120 & 26 & 120 & 120 \\
\hline NS & 10 & 120 & 120 & 14 & 15 & 13 & 120 & 46 & 40 & 120 & 71 & 106 & 44 \\
\hline
\end{tabular}

Table 3. $T_{\text {opt }}$ obtained by the different metrics at $50 \mathrm{~cm}$ depth. 
Table 4

\begin{tabular}{|c|c|c|c|c|c|c|c|c|c|c|c|c|c|}
\cline { 2 - 15 } \multicolumn{1}{c|}{} & E10 & F6 & H9 & H13 & J12 & J14 & L3 & M5 & M9 & N9 & O7 & CAR & Area-Average \\
\hline R & 1 & 4 & 1 & 1 & 5 & 2 & 4 & 1 & 19 & 9 & 3 & 17 & 6 \\
\hline RMSD & 1 & 47 & 13 & 5 & 4 & 6 & 9 & 9 & 19 & 13 & 51 & 27 & 11 \\
\hline CRMSD & 1 & 32 & 14 & 6 & 4 & 7 & 9 & 23 & 19 & 12 & 120 & 27 & 11 \\
\hline Bias & 1 & 120 & 1 & 1 & 1 & 1 & 120 & 1 & 120 & 120 & 26 & 1 & 120 \\
\hline NS & 1 & 47 & 13 & 5 & 4 & 6 & 9 & 9 & 19 & 13 & 51 & 27 & 11 \\
\hline
\end{tabular}

Table 4. $T_{\text {opt }}$ obtained by the different metrics at 0-50 $\mathrm{cm}$ depth. 